\title{
Patient Safety in Internal Medicine
}

\author{
Micaela La Regina, Alessandra Vecchié, \\ Aldo Bonaventura, and Domenico Prisco
}

\section{Learning Objectives/Questions Covered in the Chapter}

- How many are the adverse events (AEs) in Internal Medicine (IM)?

- What are the most frequent errors?

- How to prevent medication or identification errors?

- How to prevent AEs in invasive procedures in IM?

- How to prevent clinical reasoning errors?

- How to improve team working and communication among health operators in IM?

- What are the safety practices to be implemented in IM?

M. L. Regina $(\bowtie)$

S.S. Risk Management, ASL5 Liguria,

La Spezia, Italy

e-mail: micaela.laregina@asl5.liguria.it

A. Vecchié

Pauley Heart Center, Division of Cardiology,

Department of Internal Medicine, Virginia

Commonwealth University, Richmond, VA, USA

A. Bonaventura

Pauley Heart Center, Division of Cardiology,

Department of Internal Medicine, Virginia

Commonwealth University, Richmond, VA, USA

First Clinic of Internal Medicine, Department of Internal Medicine, University of Genoa, Genoa, Italy

D. Prisco

Department of Experimental and Clinical Medicine, University of Florence, Florence, Italy

e-mail: domenico.prisco@unifi.it

\subsection{Epidemiology of Adverse Events}

There are few specific studies on epidemiology of AEs in IM. Most of them are focused on particular events, such as medication, interventional procedures, or diagnostic reasoning errors.

The first historical study conducted in IM was that by Schimmel in 1960 [1]. He found that 20\% of patients admitted to a university medical service in USA experienced one or more untoward "iatrogenic" episodes. Anyway, such pioneering study was not based on the current definition of $\mathrm{AE}$ and reported only drug reactions and untoward effects of diagnostic and therapeutic procedures - the so-called diseases of medical progresses, the price to pay for modern medical care [2, 3]. Twenty years later, Steel et al. [4] reported a rate of $36 \%$ AEs in the medical service of a teaching hospital. Then, the Harvard Medical Practice Study I [5] found a rate of AEs of $3.6 \pm 0.3 \%(30.9 \pm 4.4 \%$ of them due to negligence) in IM and $7 \pm 0.5 \%$ (28 $\pm 3.4 \%$ of them due to negligence) in general surgery, and the Quality in Australian Healthcare Study (QAHCS) displayed an incidence of $6.6 \%$ in IM versus $13.8 \%$ in general surgery [6]. More recently, studies from the UK [7], the USA [8], Portugal [9], and Spain [10] reported an incidence ranging from $10 \%$ to $23.2 \%$. Fatality ranges from $2 \%$ [2] to $20 \%$ [6] in the various studies. Such large variability of incidence and severity can depend on differences in AEs definition, settings 
(only IM wards or all medical wards), study design, and severity threshold of investigators in the adjudication of events.

Medical errors - compared to surgical ones - are more preventable (73\% vs 53\% [6]; $75 \%$ vs $41 \%$ [7]), and often less overt because diagnosis and time of occurrence can be less clear and multiple providers are involved [11]. They are also associated to longer hospitalizations being directly related to the time spent in hospital $[1,12]$. Indeed, they have been defined "the hazards of hospitalization" [1]. They are more common and severe in the elderly $[10,12$, 13], and more events can occur in the same patient [1]. Lower educational level, transfer from other institutions, associated chronic conditions, severe prognosis on admission, general functional status on admission, level of awareness on admission and at discharge, associated kidney/liver failure or impaired function on admission and at discharge, number of drugs taken (on admission, during hospital stay, and at discharge), patients' knowledge about disease, medications, and their side effects [9] are other known risk factors for AEs in IM.

\subsection{Most Common Errors}

In IM, errors can occur in any step of inpatient journey from admission to discharge, and in any clinical process from clinical history collection to diagnostic work-up, drug therapy, invasive procedures, and so on. Further, they can occur before admission to IM and be recognized later, on the ward.

The words "error" and "AE" do not have the same meaning. AEs are "injuries caused by medical management rather than by the underlying disease or condition of the patient". Medical errors can result or not in patient harm, but not all of them lead to AEs. Generally, only preventable AEs imply medical errors [14]. Table 17.1 displays the most frequent AEs occurring in IM, according to hospitalization phase and process.

Table 17.1 List of the most frequent AEs in internal medicine according to hospitalization phase and process

\begin{tabular}{|c|c|c|c|}
\hline Phase & Process & Adverse event & Contributing factors \\
\hline $\begin{array}{l}\text { Pre- } \\
\text { admission }\end{array}$ & $\begin{array}{l}\text { Initial assessment and } \\
\text { treatment }\end{array}$ & $\begin{array}{l}\text { Incorrect/incomplete diagnosis } \\
\text { Incorrect/incomplete/delayed treatment } \\
\text { Reactions to drugs or transfusions } \\
\text { Inappropriate admission } \\
\text { Admission to inappropriate ward }\end{array}$ & $\begin{array}{l}\text { Lack of patient information } \\
\text { Incorrect clinical reasoning } \\
\text { Busy and noisy environment } \\
\text { Fatigue, distraction } \\
\text { Bed unavailability } \\
\text { Lack, inadequacy, or violation } \\
\text { of policies on admission } \\
\text { appropriateness and hospital } \\
\text { patient flow }\end{array}$ \\
\hline Admission & Patient identification & Tests and treatment to the wrong patient & $\begin{array}{l}\text { Identity documents not available } \\
\text { Patient cognitive impairment } \\
\text { Poor social support } \\
\text { Busy and noisy environment } \\
\text { Misunderstanding } \\
\text { Typing error } \\
\text { Inadequate or lacking } \\
\text { information technology } \\
\text { Lack, inadequacy, or violation } \\
\text { of policies }\end{array}$ \\
\hline & $\begin{array}{l}\text { Clinical history } \\
\text { collection }\end{array}$ & $\begin{array}{l}\text { Diagnostic omission or delay } \\
\text { Drug-disease interaction }\end{array}$ & \multirow{2}{*}{$\begin{array}{l}\text { Inadequate skills } \\
\text { Physician knowledge deficit } \\
\text { Distraction, fatigue } \\
\text { Busy and noisy environment } \\
\text { Outlier status } \\
\text { Patient cognitive impairment } \\
\text { Poor social support } \\
\text { Lack of policy } \\
\text { Inadequate or lacking } \\
\text { information technology }\end{array}$} \\
\hline & $\begin{array}{l}\text { Medication } \\
\text { recognition }\end{array}$ & $\begin{array}{l}\text { Preventable adverse drug reactions, } \\
\text { including withdrawal reactions } \\
\text { Unintentional drug discrepancies } \\
\text { Administration delay }\end{array}$ & \\
\hline
\end{tabular}




\begin{tabular}{|c|c|c|c|}
\hline \multirow[t]{3}{*}{ Phase } & Process & Adverse event & Contributing factors \\
\hline & Physical examination & $\begin{array}{l}\text { Diagnostic omission or delay } \\
\text { Drug-disease interaction }\end{array}$ & $\begin{array}{l}\text { Inadequate skills } \\
\text { Superficial examination } \\
\text { Knowledge deficit } \\
\text { Distraction, fatigue } \\
\text { Busy and noisy environment } \\
\text { Outlier status }\end{array}$ \\
\hline & $\begin{array}{l}\text { Initial diagnosis and } \\
\text { therapy }\end{array}$ & $\begin{array}{l}\text { Wrong, delayed, or omitted diagnosis or } \\
\text { treatment } \\
\text { Hurry, external pressure } \\
\text { Premature closure }\end{array}$ & $\begin{array}{l}\text { Inadequate skills } \\
\text { Knowledge deficit } \\
\text { Missed diagnostic clues } \\
\text { Distraction, fatigue } \\
\text { Busy and noisy environment } \\
\text { Inadequate or lacking } \\
\text { computerized order entry }\end{array}$ \\
\hline \multirow[t]{3}{*}{$\begin{array}{l}\text { Hospital } \\
\text { stay }\end{array}$} & $\begin{array}{l}\text { Clinical monitoring; } \\
\text { response to } \\
\text { pathological findings }\end{array}$ & $\begin{array}{l}\text { Unexpected death or clinical worsening } \\
\text { Unexpected intensive care transfer } \\
\text { Diagnostic or therapeutic omission or } \\
\text { delay }\end{array}$ & $\begin{array}{l}\text { Unexperienced team } \\
\text { High workload } \\
\text { Patient unable to ask for help } \\
\text { Lack, inadequacy, or violation } \\
\text { of policies }\end{array}$ \\
\hline & Medication process & $\begin{array}{l}\text { Adverse drug reactions due to: ordering/ } \\
\text { storing errors, inappropriate, or wrong } \\
\text { prescription, wrong administration } \\
\text { Drug-drug and drug-disease } \\
\text { interactions }\end{array}$ & $\begin{array}{l}\text { Wrong identification or } \\
\text { transcription } \\
\text { Knowledge deficit } \\
\text { Medical record not available, } \\
\text { illegible, not informative } \\
\text { Allergy or contraindications not } \\
\text { assessed } \\
\text { Inadequate or lacking } \\
\text { computerized order entry } \\
\text { Lack of supervision } \\
\text { Poor teamwork } \\
\text { Lack, inadequacy, or violation } \\
\text { of policies } \\
\text { Distraction, fatigue } \\
\text { Busy and noisy environment }\end{array}$ \\
\hline & Diagnostic work-up & $\begin{array}{l}\text { Wrong, delayed, or omitted diagnosis or } \\
\text { treatment } \\
\text { Hurry, external pressure } \\
\text { Premature closure }\end{array}$ & $\begin{array}{l}\text { Inadequate skills } \\
\text { knowledge deficit } \\
\text { Missed diagnostic clues } \\
\text { Medical record not available, } \\
\text { illegible, not informative } \\
\text { Missed request } \\
\text { Allergy or contraindications not } \\
\text { assessed } \\
\text { Poor planning } \\
\text { Poor teamwork } \\
\text { Lack of supervision } \\
\text { Inadequate or lacking } \\
\text { computerized order entry } \\
\text { Distraction, fatigue } \\
\text { Busy and noisy environment }\end{array}$ \\
\hline
\end{tabular}


Table 17.1 (continued)

\begin{tabular}{|c|c|c|c|}
\hline Phase & Process & Adverse event & Contributing factors \\
\hline & Consultations & $\begin{array}{l}\text { Identification errors } \\
\text { Wrong, delayed, or omitted diagnosis or } \\
\text { treatment }\end{array}$ & $\begin{array}{l}\text { See identification errors } \\
\text { Planning deficit } \\
\text { Medical record not available, } \\
\text { illegible, not informative } \\
\text { Inadequate skills } \\
\text { knowledge deficit } \\
\text { Missed diagnostic clues } \\
\text { Inadequate or lacking } \\
\text { computerized order entry } \\
\text { Missed request } \\
\text { Poor teamwork } \\
\text { Distraction, fatigue } \\
\text { Busy and noisy environment }\end{array}$ \\
\hline & Invasive procedures & $\begin{array}{l}\text { Wrong procedure, wrong patient, or } \\
\text { wrong site } \\
\text { Omitted or delayed procedure } \\
\text { Preventable complications (i.e., } \\
\text { pneumothorax during thoracentesis) }\end{array}$ & $\begin{array}{l}\text { See identification errors } \\
\text { Inadequate skills } \\
\text { Inappropriate timing or } \\
\text { indication } \\
\text { Patient not informed and } \\
\text { informed consent not signed } \\
\text { Uncooperative patient } \\
\text { Medical record not available, } \\
\text { illegible, not informative or } \\
\text { updated } \\
\text { Poor planning } \\
\text { Allergy or contraindications not } \\
\text { assessed } \\
\text { Missed request } \\
\text { Unexperienced operator } \\
\text { Lack of supervision } \\
\text { Lack or inadequacy of devices } \\
\text { Inadequate or lacking } \\
\text { computerized order entry } \\
\text { Distraction, fatigue } \\
\text { Busy and noisy environment } \\
\text { Lack, inadequacy, or violation } \\
\text { of policies }\end{array}$ \\
\hline & General care & $\begin{array}{l}\text { Falls, delirium, healthcare-related } \\
\text { infections (HAI), suicide, entrapment, } \\
\text { wandering, healthcare-related venous } \\
\text { thromboembolism, etc. }\end{array}$ & $\begin{array}{l}\text { Unsuitable footwear } \\
\text { Wet floor } \\
\text { Busy and noisy environment } \\
\text { Inappropriate or omitted basic } \\
\text { care } \\
\text { Gloves, soap, water, or alcohol } \\
\text { hand-rub unavailable or } \\
\text { underused } \\
\text { Inadequate skills } \\
\text { knowledge deficit } \\
\text { Lack, inadequacy, or omission } \\
\text { of risk stratification } \\
\text { Medical record not updated, } \\
\text { illegible, or not informative } \\
\text { Poor teamwork } \\
\text { Lack of supervision } \\
\text { Poor vigilance } \\
\text { Poor or omitted patient education } \\
\text { Fragile patient } \\
\text { Patient cognitive impairment } \\
\text { Lack, inadequacy, or violation } \\
\text { of policies }\end{array}$ \\
\hline
\end{tabular}


Table 17.1 (continued)

\begin{tabular}{|c|c|c|c|}
\hline \multirow[t]{3}{*}{ Phase } & Process & Adverse event & Contributing factors \\
\hline & Handover & $\begin{array}{l}\text { Diagnostic or therapeutic omission or } \\
\text { delay } \\
\text { Unexpected death or clinical worsening }\end{array}$ & $\begin{array}{l}\text { Unexperienced team } \\
\text { Inadequate skills } \\
\text { Lack of structured handover } \\
\text { Busy and noisy environment } \\
\text { Distraction, fatigue } \\
\text { Poor teamwork } \\
\text { Lack, inadequacy, or violation } \\
\text { of policy }\end{array}$ \\
\hline & $\begin{array}{l}\text { Communication to } \\
\text { patient and/or } \\
\text { caregiver }\end{array}$ & $\begin{array}{l}\text { Privacy failure } \\
\text { Communications provided to people not } \\
\text { authorized by the patient } \\
\text { Diagnostic or therapeutic omission or } \\
\text { delay due to poor or absent compliance } \\
\text { with care team indications or missed } \\
\text { information } \\
\text { Patient/caregiver dissatisfaction }\end{array}$ & $\begin{array}{l}\text { Inadequate non-technical skills } \\
\text { Lack or non-compliance with ad } \\
\text { hoc protocols } \\
\text { High workload } \\
\text { Lack of time } \\
\text { Poor teamwork } \\
\text { Misunderstanding } \\
\text { Patient cognitive impairment } \\
\text { Poor social support } \\
\text { Organizational failure (lack of } \\
\text { reference operators) }\end{array}$ \\
\hline \multirow[t]{2}{*}{ Last day } & Discharge planning & $\begin{array}{l}\text { Canceled or delayed discharge } \\
\text { Lack of planning controls and follow-up } \\
\text { Early readmission for the same reason }\end{array}$ & $\begin{array}{l}\text { Poor teamwork } \\
\text { Poor decision-making } \\
\text { Patient/caregiver not engaged } \\
\text { Poor patient/caregiver education } \\
\text { Pressure to discharge } \\
\text { Poor social support } \\
\text { No anticipatory prescribing } \\
\text { Lack, inadequacy, or violation } \\
\text { of policy }\end{array}$ \\
\hline & Discharge & $\begin{array}{l}\text { Discharge letter to the wrong patient } \\
\text { Incomplete discharge letter } \\
\text { Wrong or inappropriate discharge } \\
\text { destination } \\
\text { Unintentional drug discrepancies } \\
\text { Adverse drug reactions } \\
\text { Omitted or delayed diagnosis } \\
\text { communication } \\
\text { Omitted or delayed treatment }\end{array}$ & $\begin{array}{l}\text { See identification errors } \\
\text { Medical record not available, } \\
\text { illegible, not informative or } \\
\text { updated } \\
\text { Pending tests results } \\
\text { Busy and noisy environment } \\
\text { Distraction, fatigue } \\
\text { Pressure to discharge } \\
\text { Poor teamwork and } \\
\text { communication } \\
\text { Poor multidisciplinary } \\
\text { assessment } \\
\text { Poor medication reconciliation } \\
\text { Medications not available } \\
\text { Medical devices not available or } \\
\text { malfunctioning } \\
\text { No patient recall ongoing results } \\
\text { Poor patient/caregiver education } \\
\text { Lack, inadequacy, or violation } \\
\text { of policies }\end{array}$ \\
\hline
\end{tabular}

AEs in IM have been classified variously, e.g. according to the clinical process or the nature of disorder caused by AEs [7, 9] (see Tables 17.2 and 17.3). It is disappointing how the frequency of certain AEs has worsened in decades: healthcare-associated infections (HAIs) passed from $9.5 \%$ in 1960 [1] to $21.4 \%$ in 2008 [10].

When you think about the potential most frequent errors in IM, you probably think mainly about medication and diagnostic errors since 
Table 17.2 Types and preventability of AEs in IM [9]

\begin{tabular}{l|l|l}
\hline Categories & $\begin{array}{l}\text { Rate } \\
(\%)\end{array}$ & $\begin{array}{l}\text { Preventability } \\
(\%)\end{array}$ \\
\hline General care & 16.4 & 47.8 \\
\hline Medication process & 37.8 & 34 \\
\hline $\begin{array}{l}\text { Healthcare-related } \\
\text { infections }\end{array}$ & 21.4 & 16.7 \\
\hline Invasive procedures & 21.4 & 40 \\
\hline Diagnostic process & 2.8 & 100 \\
\hline
\end{tabular}

Table 17.3 Types of AEs, classified according to the nature of resulting disorder [11]

\begin{tabular}{l|l}
\hline Disorders & Rate $(\%)$ \\
\hline Infectious & 24 \\
\hline Electrolytic & 18 \\
\hline Metabolic/endocrine & 12 \\
\hline Hematological/coagulation & 9 \\
\hline Gastrointestinal & 8 \\
\hline Neurological & 4 \\
\hline Cardiovascular & 2.5 \\
\hline Skin/allergic & 2 \\
\hline
\end{tabular}

medical diagnosis and therapy are its core business. Diagnostic errors -more appropriately defined as "decision-making errors"- account for $10-15 \%$ in complex disciplines, such as IM, compared to $2-5 \%$ of perceptive ones (dermatology or radiology) [15]. Medication errors are highly prevalent among older patients or patients with multiple comorbidities and polypharmacy [16], all patients typically admitted to IM. Moreover, healthcare-acquired infections are likely to be another common AE in IM, favored by intravascular catheters and immunosuppressant treatments [17].

\subsubsection{Patient Identification Errors}

Identification errors (IEs) are commonly associated with surgery, but they can occur in every setting. Many other medical errors, included in this review, such as medication or blood transfusion errors, can result from patient misidentification at the point of care as well as at registration. IEs usually affect more people. When a patient receives a medication intended for another patient, the harm is done to the patient receiving the wrong medica- tion and to that who fails to receive the correct treatment [18]. A recent review from ECRI institute disclosed that $72 \%$ of IEs occur at the point of care and $12.6 \%$ at registration. Diagnostic and therapeutic procedures are involved in $36 \%$ and $22 \%$ of cases respectively, and consequences may be fatal [18]. Information technology amplified the problem, as IEs can generate duplicate medical records or mistaken identity. There are no specific studies on IEs in IM, but increasing staff workload and patients cognitive impairment make them a non-negligible problem.

The main barrier to IEs is cultural: the awareness of the correct identification and of misidentification consequences must be improved, so that health operators spontaneously abandon incorrect practice. Figure 17.1 summarizes what to do and not to do to prevent IEs. Technology (patient's palm scan, bar-code wristband, radiofrequency identification system, etc.) can help but cannot substitute the role of humans. One can scan the bar-code wristband of the right patient, but administrate the drugs to another one. Patients' education and empowerment are equally important [18].

\subsubsection{Clinical Reasoning Errors}

Errors in diagnostic and management process can be considered together as clinical reasoning errors (CREs) [19] or decision-making errors, as diagnostic and management reasoning can be similarly conceptualized.

According to the American National Academy of Medicine (previous Institute of Medicine), a diagnostic error is a failure to: (a) establish an accurate and timely explanation of the patient's health problem(s) or (b) communicate that explanation to the patient. This definition includes: wrong, delayed, or omitted diagnosis [20]. The incidence of diagnostic errors varies according to definition, discipline, and research approach. For instance, 1 in 10 diagnoses are wrong (according to "secret shoppers" approach that uses "secret patients" to provide detailed, unbiased insights, and feedback on healthcare processes), 1 in 10-20 autopsies identifies major diagnostic dis- 
Fig. 17.1 What healthcare operators have to do and not to do to avoid patient identification errors

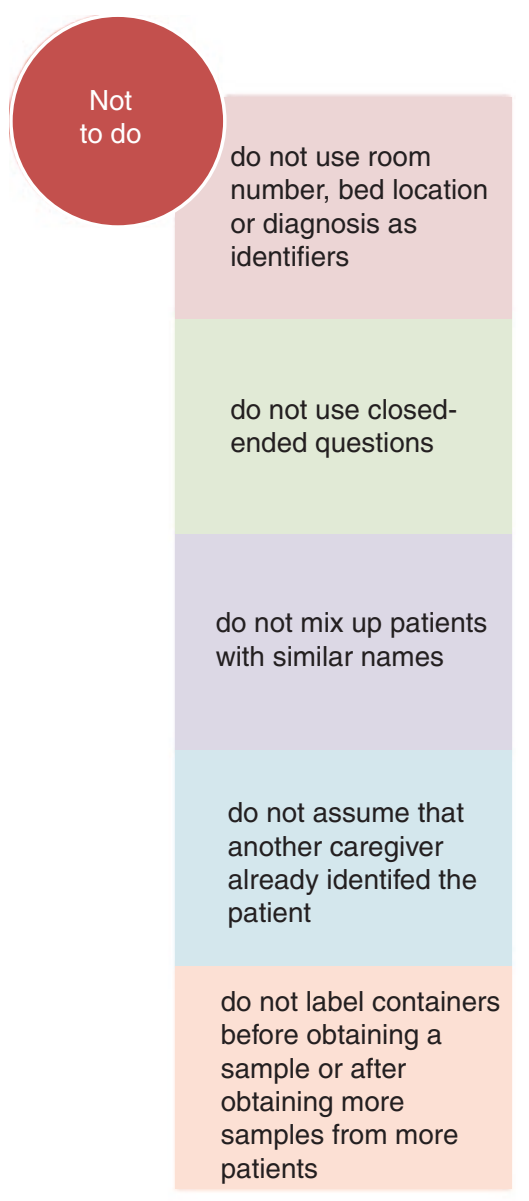
use open-ended
questions

minimize noise and interruptions during identification

put patients with similar name in different locations of the ward

\author{
label specimen \\ containers in presence \\ of patients
}

Use barcode systems to minimize the risk, especially in case of invasive procedures or high risk medications crepancies, 1 in 3 patients have experienced a diagnostic error (according to patients' survey), 1 in 20 patients will experience a diagnostic error every year (according to chart review). They are the most common cause for malpractice claims [21], and about half of physicians admit at least a diagnostic error per month and perceive diagnostic errors as the most dangerous (according to physicians' survey) [22].
The most commonly missed or delayed diseases are: pulmonary embolism and drug reaction or overdose $(2.5 \%)$, lung cancer $(3.9 \%)$, colorectal cancer $(3.6 \%)$, acute coronary syndrome $(3.1 \%)$, breast cancer $(2.9 \%)$, and stroke $(2.6 \%)$ [23]. Physicians overestimate their diagnostic ability: only $10 \%$ of clinicians admit they performed any error in diagnosis over the past year, but up to $40 \%$ of diagnoses about which cli- 
nicians were certain resulted wrong at autopsy [24]. Further, even when diagnosis is right, management errors can arise: 1 in 2 patients with acute or chronic diseases do not receive evidencebased therapies and 1 in 3-5 receive unnecessary and/or potentially dangerous drugs or investigations [19].

A third of CREs derive from deficits of execution (slips, lapses, or oversights in carrying out appropriate management in correctly diagnosed patients), but almost half are errors of reasoning or decision quality (failure to elicit, synthesize, decide, or act on clinical information).

Death or permanent disability result in $25 \%$ of cases, and at least three quarters of them are considered highly preventable [22].

A cornerstone of research on CREs in IM is the work by Graber et al. [25]. They analyzed 100 cases and grouped diagnostic errors in three categories:

- no-fault errors (in case of masked or unusual disease presentation or non-collaborative patient) $7 \%$

- system-related errors (technical failure and equipment problems or organizational flaws) $19 \%$

- cognitive errors (faulty knowledge, data gathering, or synthesis) $28 \%$.

Coexisting system-related and cognitive errors were reported in $46 \%$ of cases. Further, wrong diagnosis was characterized by a predominance of cognitive errors ( $92 \%$ vs $50 \%$ ), whereas delayed diagnosis by the predominance of system-related ones ( $89 \%$ vs $36 \%$ ). Cases where discrepancy resulted from autopsy were mainly due to cognitive factors ( $90 \%$ vs $10 \%$ ). Overall, 228 system-related factors and 320 cognitive factors, averaging 5.9 per case, were identified [26]. Among cognitive factors, faulty data gathering $(14 \%)$ or synthesis $(83 \%)$ resulted more frequently involved than faulty knowledge (3\%) [26].

Clinical reasoning can proceed analytically or non-analytically (Table 17.4) to generate diagnostic hypotheses, investigations, and treatment. Analytical reasoning (also called "hypotheticdeductive model") is commonly used by younger physicians or in unfamiliar or unusual cases and is based on lists of differential diagnoses and gathering of information to validate such diagnoses. Non-analytical reasoning is faster and based on mental heuristics (maxims, shortcuts, rules of thumb) or pattern recognition. In practice, physician compare current patient's symptoms/signs with previous cases, collected through clinical experience and/or study and get the right diagnosis in few seconds [27]. One type does not exclude the other and they can be mutually used in the same patient. None of them is error-proof. If mental heuristics and pattern recognition are efficient and accurate in many situations, they can also predispose to errors, as patient's picture does not always fit the expected pattern, because of an atypical presentation, comorbidities, or

Table 17.4 Types of clinical reasoning: a comparison [27]

\begin{tabular}{l|l|l}
\hline Non-analytical (system 1) & Characteristics & Analytical (system 2) \\
\hline $\begin{array}{l}\text { Intuitive (based on pattern } \\
\text { recognition and heuristic) }\end{array}$ & Modality & Hypothetic-deductive \\
\hline $\begin{array}{l}\text { Developed through clinical } \\
\text { experience and study }\end{array}$ & Development \\
\hline $\begin{array}{l}\text { Commonly used by expert/senior } \\
\text { physicians }\end{array}$ & Application & $\begin{array}{l}\text { Generation of list of diagnoses to } \\
\text { be validated }\end{array}$ \\
\hline $\begin{array}{l}\text { Minor cognitive load } \\
\text { Automatic, unconscious }\end{array}$ & Awareness & $\begin{array}{l}\text { Commonly used by not expert/ } \\
\text { younger physicians } \\
\text { Commonly used in atypical or } \\
\text { unfamilial cases }\end{array}$ \\
\hline $\begin{array}{l}\text { Diagnosis in } 10 \mathrm{~s} \\
\text { More efficient }\end{array}$ & Time & $\begin{array}{l}\text { Major cognitive load } \\
\text { Conscious }\end{array}$ \\
\hline
\end{tabular}


evolving diseases [28]. Another Achille's heel of non-analytical reasoning (N-AR) are biases, constructs founded on perceptions, prejudices or ideologies, outside of critical thinking. Bias can be distinguished in internal or external to the clinicians [19] either in cognitive or affective bias
[27] (see Table 17.5). Breakdowns in analytical reasoning most often derive from not following appropriate diagnostic "rules" and include: missing key data, inadequate review of existing data, deficits in medical knowledge, lacking skills in evidence-based practice and decision-making,

Table 17.5 Bias and heuristics in clinical reasoning: examples and corrective strategies [19]

\begin{tabular}{|c|c|c|c|}
\hline Bias & Description & Example & Corrective strategy \\
\hline Anchoring & $\begin{array}{l}\text { Tendency to fixate on first } \\
\text { impression and not to } \\
\text { consider further } \\
\text { information available }\end{array}$ & $\begin{array}{l}\text { The physician diagnosed a viral } \\
\text { meningitis instead of cervical } \\
\text { osteomyelitis on the basis of high } \\
\text { fever and neck pain, ignoring } \\
\text { neck pain worsened not only on } \\
\text { flexion, but also on palpation and } \\
\text { previous fore-harm wound }\end{array}$ & $\begin{array}{l}\text { Think beyond your } \\
\text { favorite diagnosis or first } \\
\text { impression } \\
\text { Reconsider initial } \\
\text { diagnosis when new data } \\
\text { or unexpected clinical } \\
\text { course }\end{array}$ \\
\hline Availability & $\begin{array}{l}\text { Tendency to accept the } \\
\text { diagnosis that more easily } \\
\text { comes to mind because of } \\
\text { recent observation rather } \\
\text { than to consider } \\
\text { prevalence and incidence } \\
\text { of such diagnosis }\end{array}$ & $\begin{array}{l}\text { The physician diagnosed a viral } \\
\text { meningitis instead of cervical } \\
\text { osteomyelitis, as he had just seen } \\
\text { a case of viral meningitis }\end{array}$ & $\begin{array}{l}\text { Consider always disease } \\
\text { prevalence and incidence }\end{array}$ \\
\hline Confirmation & $\begin{array}{l}\text { To look only for signs and } \\
\text { symptoms that confirm } \\
\text { your favorite hypothesis } \\
\text { or to interpret clinical } \\
\text { findings only to support } \\
\text { such hypothesis, without } \\
\text { looking for or even } \\
\text { disregarding opposite } \\
\text { evidences }\end{array}$ & $\begin{array}{l}\text { The physician diagnosed a skin } \\
\text { rash under the axilla of a diabetic } \\
\text { patient as intertrigo missing a } \\
\text { diagnose of erythema migrans } \\
\text { due to Lyme disease }\end{array}$ & $\begin{array}{l}\text { Utilize an objective tool, } \\
\text { such as a differential } \\
\text { diagnosis checklist, to } \\
\text { verify if diagnosis } \\
\text { correlates with technical } \\
\text { findings }\end{array}$ \\
\hline $\begin{array}{l}\text { Diagnosis } \\
\text { momentum bias }\end{array}$ & $\begin{array}{l}\text { To consider definite a } \\
\text { diagnosis without } \\
\text { evidence, but due to a } \\
\text { label applied to the first } \\
\text { contact and transmitted by } \\
\text { all the people who took } \\
\text { care of the patient }\end{array}$ & $\begin{array}{l}\text { The physician attributed to } \\
\text { alcohol withdrawal syndrome the } \\
\text { psychomotor agitation of a patient } \\
\text { with a sticky label of alcoholic, } \\
\text { missing a life-threatening sepsis }\end{array}$ & $\begin{array}{l}\text { Critically review } \\
\text { diagnoses of others and } \\
\text { look for evidence to } \\
\text { support them }\end{array}$ \\
\hline Framing ${ }^{\mathrm{a}}$ & $\begin{array}{l}\text { To decide on options } \\
\text { based on whether the } \\
\text { options are presented with } \\
\text { positive or negative } \\
\text { connotations or to be } \\
\text { influenced by the context }\end{array}$ & $\begin{array}{l}\text { The physician may decide to } \\
\text { request a cranial CT scan in the } \\
\text { same patient more often if it has } \\
\text { been presented as associated with } \\
90 \% \text { of true positives than } 10 \% \text { of } \\
\text { false negatives } \\
\text { The physician may diagnose more } \\
\text { easily a ruptured abdominal } \\
\text { aneurysm in ER than in outpatient } \\
\text { clinic }\end{array}$ & Change perspective \\
\hline Gambler's fallacy & $\begin{array}{l}\text { To believe a diagnosis less } \\
\text { probable, if it occurred in } \\
\text { several previous patients }\end{array}$ & $\begin{array}{l}\text { The physician missed a diagnosis } \\
\text { of pulmonary embolism as he } \\
\text { diagnosed four cases of } \\
\text { pulmonary embolism in the last } \\
\text { week }\end{array}$ & $\begin{array}{l}\text { Consider always pre-test } \\
\text { probability }\end{array}$ \\
\hline
\end{tabular}


Table 17.5 (continued)

\begin{tabular}{|c|c|c|c|}
\hline Bias & Description & Example & Corrective strategy \\
\hline $\begin{array}{l}\text { Multiple alternative } \\
\text { bias }\end{array}$ & $\begin{array}{l}\text { To reduce differential } \\
\text { diagnosis to few more } \\
\text { familial hypotheses, when } \\
\text { multiple options are } \\
\text { available }\end{array}$ & $\begin{array}{l}\text { The physician missed a rare } \\
\text { diagnosis of familial } \\
\text { Mediterranean fever and } \\
\text { submitted the patient to surgery } \\
\text { for appendicitis }\end{array}$ & \multirow[t]{2}{*}{$\begin{array}{l}\text { Utilize an objective tool, } \\
\text { such as a differential } \\
\text { diagnosis checklist } \\
\text { Verify if diagnosis } \\
\text { correlates with technical } \\
\text { findings }\end{array}$} \\
\hline Outcome bias & $\begin{array}{l}\text { To opt for the diagnosis } \\
\text { associated with the best } \\
\text { outcome, valuing more } \\
\text { physician hope than } \\
\text { clinical data }\end{array}$ & $\begin{array}{l}\text { The physician interpreted as } \\
\text { benign a lung nodule, instead to } \\
\text { order further investigations }\end{array}$ & \\
\hline $\begin{array}{l}\text { Frequency gambling } \\
\text { bias and worst-case } \\
\text { bias }\end{array}$ & $\begin{array}{l}\text { In ambiguous clinical } \\
\text { picture, to opt for a benign } \\
\text { diagnosis, assuming } \\
\text { benign diseases are more } \\
\text { common. } \\
\text { It is opposite to the } \\
\text { worst-case bias }\end{array}$ & $\begin{array}{l}\text { The physician interpreted the } \\
\text { poly-globulia as reactive rather } \\
\text { than as a proliferative disorder in } \\
\text { a heavy smoker }\end{array}$ & $\begin{array}{l}\text { Broaden the history to } \\
\text { search for other causes or } \\
\text { associations }\end{array}$ \\
\hline $\begin{array}{l}\text { Posterior probability } \\
\text { error }\end{array}$ & $\begin{array}{l}\text { To assume that a patient } \\
\text { presenting with the same } \\
\text { symptoms has always the } \\
\text { same disease }\end{array}$ & $\begin{array}{l}\text { The physician diagnosed heart } \\
\text { failure instead of pulmonary } \\
\text { embolism in a patient presenting } \\
\text { with dyspnea and a repeated } \\
\text { hospital admissions for heart } \\
\text { failure }\end{array}$ & \multirow[t]{4}{*}{$\begin{array}{l}\text { Use a differential } \\
\text { diagnosis checklist and } \\
\text { rule out worst-case } \\
\text { scenario } \\
\text { Consider prevalence and } \\
\text { incidence of any } \\
\text { hypothesis }\end{array}$} \\
\hline $\begin{array}{l}\text { Search satisfying } \\
\text { bias }\end{array}$ & $\begin{array}{l}\text { In presence of a main } \\
\text { diagnosis, to stop to look } \\
\text { for secondary ones. } \\
\text { In this way, the physician } \\
\text { will miss comorbidities, } \\
\text { complications, and } \\
\text { additional diagnoses }\end{array}$ & $\begin{array}{l}\text { To attribute to hypertensive heart } \\
\text { disease the atrial fibrillation } \\
\text { occurred in a patient with } \\
\text { essential hypertension, missing } \\
\text { hyperthyroidism }\end{array}$ & \\
\hline Sunk cost bias ${ }^{\mathrm{a}}$ & $\begin{array}{l}\text { The tendency to pursue a } \\
\text { course of action, even } \\
\text { after it has proved to be } \\
\text { suboptimal, because } \\
\text { resources have been } \\
\text { invested in that course of } \\
\text { action }\end{array}$ & $\begin{array}{l}\text { The physician continued to look } \\
\text { for a cancer in a patient with } \\
\text { fatigue, even if investigations are } \\
\text { repeatedly negative } \\
\text { "Do not cling to a mistake just } \\
\text { because you spent a lot of time in } \\
\text { making it" Aubrey De Graf }\end{array}$ & \\
\hline Visceral bias & $\begin{array}{l}\text { To opt for a diagnosis } \\
\text { being influenced by } \\
\text { emotions }\end{array}$ & $\begin{array}{l}\text { The physician attributed } \\
\text { iron-deficiency anemia to } \\
\text { hypermenorrhea in a patient her } \\
\text { age without looking for bowel } \\
\text { diseases }\end{array}$ & \\
\hline Commission bias & $\begin{array}{l}\text { Tendency to do something } \\
\text { even if it is not supported } \\
\text { by robust evidence and } \\
\text { may in fact do harm }\end{array}$ & $\begin{array}{l}\text { The physician complied with the } \\
\text { request for lumbar puncture of the } \\
\text { parents of an 18-year-old girl with } \\
\text { fever and headache to rule out } \\
\text { meningococcal meningitis } \\
\text { although the neutrophil count was } \\
\text { normal. The girl then developed a } \\
\text { severe post-puncture headache } \\
\text { and was admitted to hospital }\end{array}$ & $\begin{array}{l}\text { Consider always evidence } \\
\text { and balance benefits and } \\
\text { risks }\end{array}$ \\
\hline
\end{tabular}


Table 17.5 (continued)

\begin{tabular}{|c|c|c|c|}
\hline Bias & Description & Example & Corrective strategy \\
\hline Premature closure & $\begin{array}{l}\text { To stop seeking other } \\
\text { information after reaching } \\
\text { a diagnostic conclusion }\end{array}$ & $\begin{array}{l}\text { The radiologist did not see a } \\
\text { second fracture, after the first has } \\
\text { been identified }\end{array}$ & $\begin{array}{l}\text { Review the case, seek } \\
\text { other opinions (e.g., } \\
\text { radiology backup), and } \\
\text { consult objective } \\
\text { resources (e.g., an } \\
\text { orthopedic review that } \\
\text { might include mention of } \\
\text { a common concomitant } \\
\text { fracture) }\end{array}$ \\
\hline $\begin{array}{l}\text { Representativeness } \\
\text { bias }\end{array}$ & $\begin{array}{l}\text { To make a diagnosis } \\
\text { considering only typical } \\
\text { manifestations of a } \\
\text { disease }\end{array}$ & $\begin{array}{l}\text { The physician missed a diagnosis } \\
\text { of myocardial infarction } \\
\text { presenting with nausea and } \\
\text { vomiting }\end{array}$ & $\begin{array}{l}\text { Consider atypical } \\
\text { manifestations, especially } \\
\text { in women }\end{array}$ \\
\hline Extrapolation bias ${ }^{\mathrm{a}}$ & $\begin{array}{l}\text { To generalize experiences } \\
\text { and clinical trial results to } \\
\text { groups of patients in } \\
\text { whom intended actions } \\
\text { have not been properly } \\
\text { evaluated }\end{array}$ & $\begin{array}{l}\text { The physician ordered a CT scan } \\
\text { to exclude an acute coronary } \\
\text { syndrome in a patient with } \\
\text { previous coronary artery bypass } \\
\text { grafting (CABG) }\end{array}$ & $\begin{array}{l}\text { Use tests for evidence- } \\
\text { based indications }\end{array}$ \\
\hline
\end{tabular}

These biases can affect not only diagnostic process but also treatment decisions

erroneous consideration of tests value, poor supervision of N-AR [28]. At the end, also noisy environment, interruptions, high workload, fatigue, and time pressure can impair reasoning [27].

Health Research \& Educational Trust (HRET), Hospital Improvement Innovation Network (HIIN) team, and Society to Improve Diagnosis in Medicine (SIDM) [29] published "Diagnostic error-Change Package," a document including a menu of strategies and concepts that any hospital should implement (improving teamwork effectiveness and diagnostic process reliability, engaging patients and caregivers, reinforcing learning system, and optimizing cognitive performances of clinicians) [29]. For this last aim, several tools are available: (a) checklists for diagnostic process such as CATCH (Comprehensive history and physical exam, Alternate explanations, Take a diagnostic timeout to be certain, Consider critical diagnoses not be missed, Help if needed) [30]; (b) mnemonic decision support tools like VITAMIN CC \& D checklist (Vascular, Infection \& Intoxication, Trauma \& Toxins, Autoimmune, Metabolic, Idiopathic \& Iatrogenic, Neoplastic, Congenital, Conversion, Degenerative); (c) lists of Red Flags; (d) electronic decision support systems like Isabel, associated with the highest accurate diagnosis retrieval rates [31]; (e) debiasing questions (Table 17.6) [32]; (f) reflective practice by the following options:

- The crystal ball experience [29]: stop and ask: "if my diagnosis was wrong, which alternatives should I consider?"

- The ROWS (Rule Out Worst case Scenario) [29]: exclude first the most severe possible diagnoses.

- The Blue and Red Team Challenge [33], borrowed from military sector, is a safe method to improve clinical decision-making in complex clinical situations. Staff is divided into two teams: the Blue Team takes clinical history, makes the synthesis and generates diagnostic hypotheses; the Red Team acts as an independent reviewer by thinking critically about the clinical picture and identifying alternative diagnoses to those presented.

- Take 2-think, do [32] is designed to improve awareness and recognition of potential errors and reduce morbidity and mortality of wrong, missed, or delayed diagnosis. Literally, it means "Take 2 minutes to deliberate diagnosis" to verify if there are situations that need a closer look or diagnosis re-evaluation (Think moment) and act (Do moment). A closer look is necessary if physician is Hungry, Angry, 
Table 17.6 "Debiasing questions" to avoid cognitive errors in high-risk situations: what should I ask myself [33]

\begin{tabular}{|c|c|}
\hline High-risk situations & Questions \\
\hline Handoff & $\begin{array}{l}\text { Is this patient handed off to } \\
\text { me from another shift? }\end{array}$ \\
\hline $\begin{array}{l}\text { External influence } \\
\text { Excessive } \\
\text { confidencein } \\
\text { collaborators or } \\
\text { colleague }\end{array}$ & $\begin{array}{l}\text { Did the patient, a nurse, or } \\
\text { another doctor suggest to me } \\
\text { this diagnosis, directly or } \\
\text { indirectly? }\end{array}$ \\
\hline $\begin{array}{l}\text { Excessive } \\
\text { self-confidence }\end{array}$ & $\begin{array}{l}\text { Did I choose the first } \\
\text { diagnosis that came to my } \\
\text { mind? }\end{array}$ \\
\hline Premature closure & $\begin{array}{l}\text { Did I consider any organ and } \\
\text { apparatus? }\end{array}$ \\
\hline $\begin{array}{l}\text { Prejudice or } \\
\text { identification }\end{array}$ & $\begin{array}{l}\text { Do not I like that patient for } \\
\text { some reason? } \\
\text { Do I have something in } \\
\text { common with that patient? }\end{array}$ \\
\hline $\begin{array}{l}\text { Noisy and/or busy } \\
\text { environment }\end{array}$ & $\begin{array}{l}\text { Was there any interruption or } \\
\text { distraction during the } \\
\text { evaluation of that patient? }\end{array}$ \\
\hline Personal fatigue & $\begin{array}{l}\text { Was I sleepy or tired during } \\
\text { that patient evaluation? }\end{array}$ \\
\hline Cognitive overload & $\begin{array}{l}\text { Am I overloaded or } \\
\text { over-extended from a } \\
\text { cognitive point of view? }\end{array}$ \\
\hline Stereotyped situation & $\begin{array}{l}\text { Am I stereotyping that } \\
\text { patient? }\end{array}$ \\
\hline $\begin{array}{l}\text { Time pressure, high } \\
\text { workload }\end{array}$ & $\begin{array}{l}\text { Am I neglecting some "must } \\
\text { not miss" diagnosis? }\end{array}$ \\
\hline
\end{tabular}

Late, or Tired (HALT), at risk of cognitive biases (e.g., context, framing bias) or in case of difficult patient engagement, knowledge deficit, time pressure, high-risk presentations; diagnosis re-evaluation if things are not going as planned, patient is deteriorating, response to treatment is not as expected, at shift change or discharge or in case of patient's/caregiver's concern. Strategies to review and challenge the diagnosis are individual strategies, i.e., Diagnostic Timeout; Team-based strategies, e.g., Red Team Blue Team Challenge; second opinion from specialist services or senior medical officer. Such approach helps to rule out the worst-case scenario, identify atypical or rare presentations, re-evaluate patients who do not improve, acknowledge patient and caregivers' concerns, recognize high-risk patient groups, favor discussion or appropriate referral and escalation for diagnostic dilemmas, effective communication in case of care transfer.

At the end, appropriate and effective clinical reasoning should be trained. The "twelve tips for teaching avoidance of diagnostic errors" and "ten commandments to reduce cognitive errors" can be helpful to this scope [32].

\subsubsection{Medication Errors}

Medication errors (MEs) are unintended, preventable events that can cause or lead to inappropriate medication use or patient harm [34]. You make MEs if you give the right medication to a wrong patient or the wrong medication/dose to the right patient, if you prescribe a medication to the wrong patient or without indication or when you forget to give a medication that was due. MEs are one of the most common medical errors occurring in every setting: $41.7 \%$ happen in care homes, $38.3 \%$ in primary care, and $20 \%$ in secondary care settings. It has been estimated that less than $1 \%$ cause harm to patients [35]. Associated harm is moderate in $26 \%$ of cases and severe in $2 \%$ [35]. They are also costly in terms of lives and resources [36].

MEs fall in the broadest category of adverse drug events (ADEs) that represent $5 \%$ of all AEs in high-income countries and $2.9 \%$ in low-middle income ones, according to WHO estimation [37]. ADEs are untoward, preventable or not, outcomes due to medications. If a patient has a skin rash due to an antibiotic, it is an ADE; if allergy was known, it is a preventable ADE. Preventable ADEs are formally MEs. Lastly, potential ADEs (pADEs) are MEs with the potential to cause an injury [38].

Given the well-known problem of underreporting of ADEs, MEs affect about 4.8-5.3\% of hospitalized patients with a significant variability by setting: intensive care is the most affected, whereas obstetrics the least as many drugs are prohibited [36, 39-41]. MEs may occur at any stage of medication process from ordering to transcription, dispensing, administering, and monitoring. About $80 \%$ happen during prescribing $(39 \%)$ or nurse administration $(38 \%)$, the 
remaining $20 \%$ during transcription and verification $(12 \%)$ or pharmacy dispensing (11\%) [42]. Any type of error can result from different proximal causes and a single proximal cause can lead to a variety of errors. For example, lack of drug knowledge can cause wrong choice, dose, frequency, route, or technique of administration. Wrong dose can result from lack of drug or patient knowledge, slip or memory lapses, transcription errors, and so on. Behind proximal causes there are latent causes or system failures. Leape et al. counted 16 different system failures, but the first seven have in common an impaired access to information and accounted for $78 \%$ of all MEs, whereas work and staff assignment have been associated to a broad range of errors such as slips, dose- and identity-checking, breakdown of allergy barriers [41].

Frequency of MEs/ADEs in IM has been poorly investigated. An 8-month prospective, cross-sectional study found that $89 \%$ of the patients experienced at least one ME during hospitalization, with a mean of 2.6 errors per patient or 0.2 errors per ordered medication. More than $70 \%$ of MEs happened during prescription. The most prevalent prescription MEs were inappropriate drug selection, prescription of unauthorized drugs or for untreated indications. The most involved drugs were cardiovascular agents followed by antibiotics, vitamins, minerals, and electrolytes [43].

MEs are more frequent and severe in the socalled high-risk situations due to high-risk patients and/or providers, medications, or settings. High-risk patients are younger or older, multi-morbid or chronic patients (with liver and/ or renal impairment), on polypharmacy [44-47]. High-risk providers are younger or not expert providers [48, 49]. High-risk systems are hospitals delivering acute care (e.g. error rates are likely higher for drugs administered intravenously compared with other routes [50]) and high-risk medications are the so-called high-alert medications (HAMs) and look-alike, sound-alike medications (LASA). HAMs have a heightened risk of causing significant patient harm when used erroneously. They include drugs with a low therapeutic index and drugs at a high risk of harm when administered by the wrong route or at wrong dosage or when other system errors occur. The acronym A-PINCH serves as a reminder of them, it stays for Anti-infective, Potassium and other electrolytes, Insulin, Narcotics and other analgesics, Chemotherapeutic agents, Heparin and other anticoagulants. LASA are drugs with similar names or boxes [50].

Although there is no standard definition, polypharmacy is generally defined as the concurrent use of five or more medications [51], over-thecounter and complementary medicines included. It increases MEs because it reduces compliance and favors timing and/or dosing errors, duplications, or omissions. Drug-drug and drug-disease interactions, instead, increase ADEs [51]. It is particularly risky in IM as it cares for polypathological patients, even if internists could be more aware and cautious, as supposed by a French study [52].

Care transition is a key moment of care for several reasons, medication safety included. It occurs when a patient moves to, or returns from, home, hospital, residential care setting or simply outpatient clinics, general practitioners' office or consultation. In care transition unintentional (changes not supported by clinical reason) and/or undocumented (motivated but not documented changes) medication discrepancies can occur [53]. They are MEs that can lead to ADEs. A mean of 1.72 unintentional discrepancies per patient have been reported at hospital admission ( 0.16 per patient potentially harmful) and 2.05 per patient ( 0.3 potentially harmful) at discharge from hospital [54].

Causes of MEs are numerous, so multiple simultaneous interventions are needed to reduce their rate and impact [36]. In recent years, information technology has been established as a cornerstone for MEs reduction. Recent meta-analysis highlighted that in hospital computerized physician's order entry is associated with a greater than $50 \%$ decline in pADEs [55], and the use of barcode assisted medication administration substantially reduced the rate of MEs and pADEs [56].

Medication reconciliation (MR) is recommended to avoid unintentional discrepancies between patients' medications across transitions 
in care. At a minimum, medication reconciliation refers to the completion of a "Best Possible Medication History" (BPMH) and the act of correcting any unintended discrepancies between a patient's previous medication regimen and the proposed medication orders at admission (from home or a healthcare facility, such as a nursing home), inpatient transfer (to or from other services or units, such as the intensive care unit), or discharge (to home or a healthcare facility). More advanced medication reconciliation involves inter-professional collaboration (e.g. a physician and nurse or pharmacist conducting medication reconciliation as a team), integration into discharge summaries and prescriptions, and provision of medication counseling to patients [23]. Medication reconciliation has also been bundled with other interventions to improve the quality of transitions in care, such as patient counseling about discharge care plans, coordination of follow-up appointments, and post-discharge telephone calls [24-26].

It refers to the completion of the BPMH and the correction of any unintended discrepancies between patient's previous therapy and that prescribed on admission to hospital or other healthcare facility, at discharge from them or in case or transfer to other wards or settings. More advanced system of MR include inter-professional collaboration (physician, nurse, pharmacist as a team), integration of MR in discharge letters and prescriptions, medication counseling to patients. It seems that MR alone cannot reduce postdischarge hospital utilization within 30 days, but it requires to be associated with other interventions such as coordinated discharge plan, counseling about discharge plan to patients, follow-up appointments and post-discharge phone calls. Evidence shows that pharmacist involvement increase intervention's success [57]. Beyond that there are several strategies that any operator can use to prevent MEs (Table 17.7).

\subsubsection{Special Focus: Oxygen and Noninvasive Ventilation}

Oxygen is actually a drug and, moreover, the most prescribed drug in hospitals. Oxygen is indicated in many critical conditions and is a life-
Table 17.7 Individual behavioral strategies to avoid medication errors

1. Write orders legibly

2. Limit verbal orders, especially in case of high alert or look-alike, sound-alike medications

3. Have always an independent double check for "high-alert drugs"

4. Eliminate the need for calculations through use of tables

5. Use pumps if indicated and available

6. Avoid dangerous abbreviations such as those in the ISMP list

7. Avoid the "trailing zero" and put always a zero before decimals

8. Take a complete medication review at any patient encounter

9. Know any drug you prescribe, dispense, or administer

10. Adjust doses to liver and/or renal function

11. Check allergies and interactions before prescription and/or administration

12. Check patient identity, drug, dosage, dose, route, and rate before prescribe, dispense, or administer

13. Ask if you are in doubt or you do not know

14. Explain the purpose of any medication introduction or withdrawal to patients, caregivers, and other team members

15. Put safety ahead of timeliness and exercise caution when you are out of the normal safety zone of practice

saving drug, as it prevents severe hypoxemia. However, it can potentially cause serious damage or even death if it is not properly administered and managed. The National Patient Safety Agency (NPSA) published in 2009 a report of 281 incidents in which an inappropriate prescription and management of oxygen caused 9 deaths and contributed to other 35 [58]. The analysis of these events highlighted various error modes: (1) failed or incorrect prescription; (2) oxygen administration without a written prescription; (3) failure to monitor or to act in the event of altered oxygen saturation levels; (4) confusion between oxygen and compressed air or other gases, erroneous flows, inadvertent disconnection of the flow; (5) empty cylinder equipment, missing equipment. Therefore, NPSA has issued a series of recommendations to improve the safety of oxygen therapy (Table 17.8).

Noninvasive mechanical ventilation, thanks to its potential for use outside intensive care, for example in IM, has been shown to significantly 
Table 17.8 Recommendations to improve safety in oxygen therapy and noninvasive ventilation [60-63]

\begin{tabular}{|c|c|}
\hline Oxygen therapy & Noninvasive ventilation \\
\hline $\begin{array}{l}\text { 1. Always ask yourself if the patient needs oxygen. Routine use of } \\
\text { oxygen in patients with myocardial infarction, stroke, or dyspnea } \\
\text { without respiratory failure is not supported by the evidence } \\
\text { 2. Prescribe oxygen indicating the target of peripheral saturation } \\
\left(\mathrm{SpO}_{2}\right) \text { to be achieved: } 94-98 \% \text { for critically hypoxemic patients } \\
\text { and } 88-92 \% \text { in patients at risk of hypercapnia (obese, } \\
\text { kyphoscoliotic and affected by other restrictive syndromes, } \\
\text { patients with neuromuscular diseases) or with manifest } \\
\text { hypercapnic respiratory failure } \\
\text { 3. Use the appropriate device. Nasal cannulas are adequate for most } \\
\text { patients; the mask with reservoir must be reserved to limited } \\
\text { cases of critically ill patients. Use a } 28 \% \text { ventimask for high-risk } \\
\text { patients with COPD or who require low-dose oxygen } \\
\text { 4. A correct oxygen prescription includes target, device, and dose } \\
\text { (flow in } 1 \text { /min and fiO }{ }_{2} \% \text { ) } \\
\text { 5. Report in medical records the results when you check blood } \\
\text { gases during oxygen therapy } \\
\text { 5. Before start oxygen, have blood gas analysis in all critical } \\
\text { patients and, in particular, if you suspect acidosis or hypercapnia. } \\
\text { Peripheral saturimetry does not provide information on pH and } \\
\text { pCO } \\
\text { 6. Monitor patients in oxygen therapy using systems for the early } \\
\text { identification of clinical deterioration (e.g., NEWS) } \\
\text { 7. In an emergency, do not delay the administration of oxygen, to } \\
\text { make the written prescription } \\
\text { 8. Educate patients, caregivers, and support staff (social and health } \\
\text { workers) to correctly manage oxygen in hospital and at home }\end{array}$ & $\begin{array}{l}\text { Organizational level } \\
\text { Short-term actions: } \\
\text { 1. Write down, share, and update a local } \\
\text { policy } \\
\text { 2. Provide a checklist for each model of } \\
\text { ventilator available in the department, in } \\
\text { particular about circuit assembly, } \\
\text { definition of controls and alarms) } \\
\text { 3. Perform and document staff training } \\
\text { and periodic retraining } \\
\text { Long-term actions: } \\
\text { 1. Check staff competences annually } \\
\text { 2. Make available the material used for } \\
\text { the training } \\
\text { 3. Create a multidisciplinary team with } \\
\text { clear roles and criteria for intervention } \\
\text { Operational level } \\
\text { 1. Offer continuous monitoring of oxygen } \\
\text { peripheral saturation to patients on } \\
\text { noninvasive mechanical ventilation } \\
\text { 2. Perform intermittent controls of pH and } \\
\text { pCO by blood gas analysis } \\
\text { 3. Provide continuous } \\
\text { electrocardiographic monitoring in case } \\
\text { of heart rate }>120 / \text { min or arrhythmias or } \\
\text { possible associated heart defects. }\end{array}$ \\
\hline
\end{tabular}

reduce mortality, the use of intubation and mechanical ventilation, especially in patients with COPD exacerbation.

A recent review [59] of AEs reported during noninvasive ventilation has shown some highrisk situations: (1) inadequate monitoring of patients unable to ask for help; (2) alarms deactivated by the staff; (3) staff not familiar with the ventilators and their proper use (e.g. if they require a $\mathrm{CO}_{2}$ valve or not; when patients bring home appliances to the hospital); (4) implementation of a new ventilator or a new interface without training. In Table 17.8, Joint Commission International [60]/British Thoracic Society/ Intensive Care Society [61] recommendations to improve the safety of noninvasive ventilation are listed.

\subsubsection{Interventional Procedure- Related Errors}

The National Institute for Health and Care Excellence (NICE) defines an "interventional procedure" as a procedure used for diagnosis and/or treatment that involves [62]:

- making a cut or a hole to gain access to the inside of a patient's body-for example, when carrying out an operation or inserting a tube into a blood vessel

- gaining access to a body cavity (such as the digestive system, lungs, womb, or bladder) without cutting into the body - for example, examining or carrying out treatment on the inside of the stomach using an instrument inserted via the mouth

- using electromagnetic radiation (which includes X-rays, lasers, gamma-rays, and ultraviolet light) — for example, using a laser to treat eye problems.

Interventional procedures most frequently carried out autonomously by the internists at bedside are: thoracentesis, paracentesis, rachicentesis, osteo-medullary biopsy, central venous accesses, joint aspirations, but literature does not provide data on their frequency. Errors during interventional procedures can cause various AEs of different severity, but apart from compli- 
cation rates there substantially no data about other quality measures. For example, we know that the most common $\mathrm{AE}$ of thoracentesis is pneumothorax occurring in up to $39 \%$ of patients [63] (10-50\% of them requiring tube thoracostomy), but we know very few about success rate, adequacy of the diagnostic specimens obtained, wait time, accuracy and completeness of clinical documentation, and patient satisfaction of thoracentesis and other procedures performed bedside on IM inpatients. On such premises, at General Hospital of Toronto an audit on procedural quality of interventional procedures was conducted in General Internal Medicine [64].

Over a 2-week period, 19 procedures (4 thoracenteses, 6 paracenteses, 8 lumbar punctures, and 1 arthrocentesis) were attempted, of which 14 at the bedside and 5 by interventional radiology. Only $7(50 \%)$ of the bedside procedures were successful. The most common reason for failure was inability to aspirate fluid. Less than $25 \%$ of bedside procedures were done on ultrasound guidance. The majority were carried out by students and residents, but only 7 (50\%) were documented as supervised. None of the operators used procedural timeouts or checklists. Over $50 \%$ of the bedside procedures were performed on evenings or weekends with less success (44\% vs $60 \%$ ), suggesting that procedures should be done during the daytime, when there is more availability of support and supervision. The quality of documentation was also suboptimal. Less than $50 \%$ of the procedures documented that the specific risks of the procedure were explained to the patient, how much local anesthetic was used, or what was the side (i.e., left or right). Communication with general practitioner was poor as well: only $66 \%$ of the discharge summaries included the date of the procedure and only $75 \%$ the results of the procedure [64]. Another study on lumbar puncture investigating for headache on an acute medical admission unit reported that documentation of position and cerebrospinal fluid (CSF) opening pressure was poor ( $42 \%$ and $32 \%$, respectively) even if essential, and only $32 \%$ had paired serum glucose measured [65].
Procedure-related errors are due to procedural and system factors [66], such as lack of clinician comfort with performing the procedure, inadequate supplies, insufficient time, or patient factors such as body habitus or characteristics of the fluid collection such as loculation. Once more, there is good evidence that clinicians are performing fewer bedside procedures and are less confident in their bedside procedural skills [67, 68]. So, interventions able to improve safety turn out to be: ultrasound guidance, use of a procedurespecific checklist, patient identification policy and pre-procedural briefing about patient characteristics and risk factors, routine review of physician-specific procedural outcomes, periodic evaluation of operators' competences, training through simulation, supervision until competence is consistently demonstrated and creation of dedicated teams [69-71], periodic assessment of procedural quality including informed consent obtained, waiting time, use of procedural timeout and sonography if needed, number of attempts, success and complication rate, diagnostic sampling quality, completeness of diagnostic tests, avoidance of waste, documentation completeness, legibility (for handwritten notes) and accuracy, wrong side errors, need for repeat procedure and patient satisfaction [64].

\subsubsection{Communication Errors}

Inter-professional communication in IM wards is complex, owing to the variety of patients' population with changing clinical conditions and constant turnover, and multiple providers' alternation [72]. A lot of information is exchanged every day among care providers in IM, through face-to-face (ward rounds, handover, briefing), synchronous (telephone or page), or asynchronous ways (clinical chart, text messages, emails, written handoff). Anyway, there are only few empirical studies that explore inter-professional communication in IM [73], even if effective inter-professional communication in such information-intensive environment is critical to achieve a safe and timely care.

The most common communication strategies in IM include: handover, ward rounds, clinical 
chart, briefing, and debriefing. In addition, there are other informal communication ways such as corridor conversation or chance hallway encounters.

\subsubsection{Handoff}

Up to $70 \%$ of sentinel events stem at least in part from miscommunications, often occurring during shift changes [74]. The transfer and acceptance of patient-care responsibility achieved through effective communication is technically called "handoff." It is a real-time process of passing patient-specific information from one caregiver/ team to another for the purpose of ensuring continuity and safety of care [75]. US International Joint Commission recommendations for handover are reported in Table 17.9 [75]. The most relevant is to refer to standardized handoff tools and methods (forms, templates, checklists, protocols, mnemonics, etc.). A recent review reported at least 24 different handoff mnemonics [76]. The minimum critical content to communicate to the receiver should include: (1) sender contact information; (2) illness assessment, including severity; (3) patient summary, including events leading up to illness or admission, hospital course, ongoing assessment, and plan of care; (4) to-do action list; (5) contingency plans; (6) allergy list; (7) code status; (8) medication list; (9) dated laboratory tests; (10) dated vital signs [75].

The most commonly used mnemonics are SBAR and its variants (I-SBARR, ISOBAR) and I-PASS. The former, developed in military setting to quickly pass information in command

Table 17.9 Recommendations to increase handover safety [77]

Recommendations of International Joint Commission

1. Have a standardized approach to handoff communication

2. Prefer communications face to face, otherwise by telephone or video conference

3. Avoid only electronic or paper communications

4. Choose locations free from interruptions and noise

5. Include multidisciplinary team and also patient and family if appropriate

6. Do not rely on the patient and/or caregiver for the transfer of important information

7. Be traceable in case of need chain [77], has been adopted in healthcare with evidence for improved patient safety. Anyway, it is more suitable for emergency calls [77]. I-PASS Handoff Bundle was developed at the Boston Children Hospital and includes team training, verbal mnemonic, and structured printed tool. Medical errors fell by $40 \%$ - from $32 \%$ of admissions at baseline to $19 \%$ of admissions 3 months during the pilot study [78]. Currently, the I-PASS Mentored Implementation Program is a collaboration with the Society for Hospital Medicine funded by AHRQ, to facilitate implementation of the I-PASS Handoff Bundle in IM [79], as it is more suitable for complex patients.

\subsubsection{Ward Round}

According to the Royal College of Physicians (RCP) and the Royal College of Nurses (RCN), ward round (WR) is "a complex clinical process during which the clinical care of inpatients is reviewed" [80]. It is also considered "a ritual of hospital life" [81] and "the cornerstone of hospital care" [82]. Undoubtedly, it is the main moment of information exchange in IM [83], critical to ensure high-quality, safe, and timely care. However, modern hospital organization is threatening effective WR, in particular because of staff shortage. In order to "save the ward round," RCP and $\mathrm{RCN}$ recently purposed to structure WR, as its standardization could warrant effectiveness and efficiency. A structured multidisciplinary WR includes four steps: (1) preparation; (2) preround briefing; (3) round; (4) post-round briefing. WR scheduling is not a negligible aspect to avoid overlapping with other activities (i.e. drug rounds, mealtimes, or visiting hours) or other team rounds in case of outliers. Inadequate scheduling can generate resources and efficiency issues but also safety problems, e.g. lack of the nurse responsible for the patient during WR and time wasted commuting to wards [80]. Preparation and pre-round briefing are critical to save time and resources for WR, post-round briefing to clearly delegate any task. A debrief should be conducted at the end of WR. Briefing and debriefing are practices borrowed from military world where they are used to assign mission tasks and verify them at the end. Briefing should be 
well-structured, concise, focused, shared, and reported in medical chart. For bedside round, $\mathrm{RCP}$ and RCN purpose a structure with precise roles and responsibilities for doctors, nurses, other professionals, and patients, listing the activities that should be carried out by any of them. In this way, everyone brings his/her competencies and opinions, decisions are taken collegially, anyone is simultaneously informed, patients and/or caregiver actively participate and are timely informed about care plan [80]. That
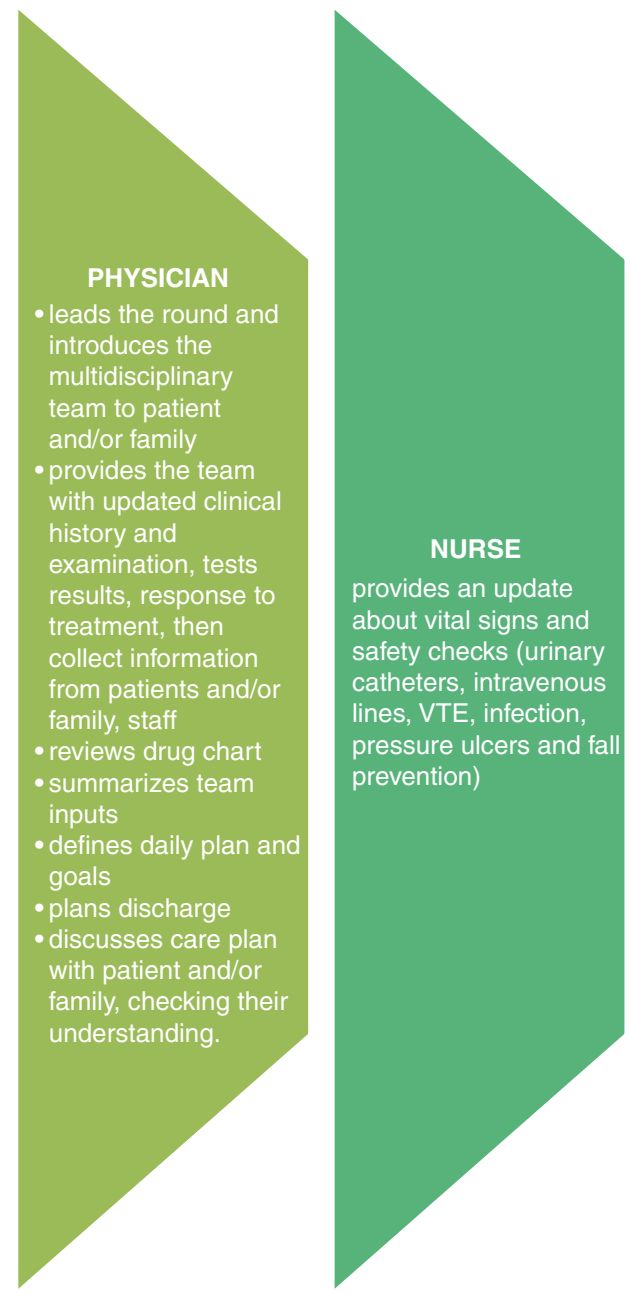

PATIENT AND/OR CAREGIVE

express their feeling or concerns, ask questions about care plan or discharge and provide any additional information.

Fig. 17.2 Roles and responsibilities of the different health professionals during bedside round

means no essential information is missed, breakdown in communication among team members and with patient or family is prevented, time and resources utilization is optimized, quality, and safety are warranted. Figure 17.2 includes a checklist for bedside round.

Other subsidiary rounds are board rounds (BRs) and intentional rounds (IRs). BRs are held away from bedside, next to a white board. They should be used to facilitate patient review but cannot replace bedside round. They can be used

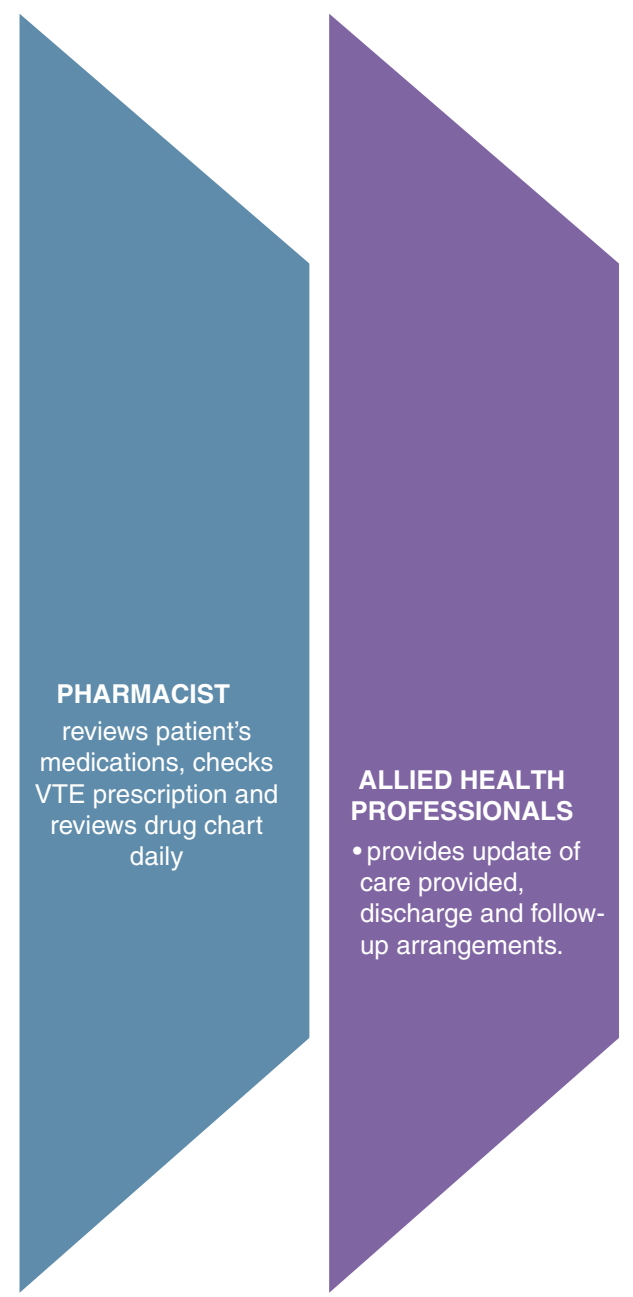


also for post-round briefing to summarize all issues, identify and prioritize tasks, and delegate responsibilities appropriately [80]. IRs are proactive nurse rounds to check patients at set intervals. During IRs, nurses assess patient's experience and essential care needs (4 P: positioning, pain, personal needs, and placement). In terms of patient safety, positioning check helps to prevent pressure ulcers, personal needs (i.e., toilet) and placement of personal items checks reduce falls. Nevertheless, IRs facilitate team to organize workload [80].

\subsubsection{Clinical Records}

Keeping clinical records (CRs) is an integral component in good professional practice and the delivery of high-quality care. Regardless of the type of documentation (electronic or paper), a good and updated CRs allow continuity and coordination of care, aid informed decision-making, avoid repetition of tests or other investigations, improve communication between the various health professionals and improve time management. Bad CRS misinform healthcare professionals and patients, prolong hospitalization, jeopardize patient care leads to serious incidents and increase medical-legal risk [84]. Figure 17.3 summarizes what to do and not to do to keep good medical records.

\subsection{Safety Practices and Implementation Strategy}

According to the Agency for Healthcare Research and Quality and the National Quality Forum " $a$ Patient Safety Practice is a type of process or structure whose application reduces the probability of adverse events resulting from exposure to the healthcare system across a range of diseases and procedures" [85].

In 2001 [86] and 2013 [85], an international panel conducted an evidence-based assessment of patient safety strategies (PSSs). The PSSs were categorized according to the following aspects: frequency and severity of the problem addressed, strength of evidence of the effective- ness of the safety strategy, the evidence or potential harmful consequence of the safety strategy, an estimation of implementation difficulties and costs. It categorizes each PSS according to the following: the scope of the underlying problem that the PSS addresses (its frequency and severity); the strength of evidence about the effectiveness of the safety strategy; the evidence or potential for harmful consequences of the strategy; a rough estimate of the cost of implementing the strategy (low, medium, or high); and an assessment of the difficulty of implementing the strategy. As a result of this process, 10 PSSs were identified as "strongly encouraged" and other 12 as "encouraged" for adoption [85].

Here, we report some safety practices relevant to IM, most of them included in the list of strongly encouraged or encouraged for adoption [87].

\subsubsection{Prevention of Age and Frailty- Related Adverse Events}

Falls. The rate of falls in acute care hospitals varies from 1 to 9 per 1000 bed-days. The first effective strategy relies on the timely recognition of patients with risk factors for falls (Table 17.10) [88]. The National Institute for Health and Care Excellence (NICE) recommends to regard as the population at risk all inpatients older than 65 and those between 50 and 64 who are identified as being at high risk of falling [89]. Actually, some tools are available to discriminate between highand low-risk patients, but they may show limitations in specific populations. Morse Falls Score (MFS) and STRATIFY Score are the two most widely validated tools. However, they were not judged to be diffusely adopted and generate greater benefits than nursing staff clinical judgment [90]. NICE guidelines do not recommend any predictive score [89]. Besides, various assessments and interventions should take place (Table 17.11): (1) all aspects of the inpatient environment —including flooring, lighting, and furniture - must be identified and addressed; (2) high-risk patients should be considered for multifactorial evaluation in order to timely identify cognitive impairment, incontinence, fall history, 
Fig. 17.3 What healthcare operators have to do and not to do to keep good clinical records

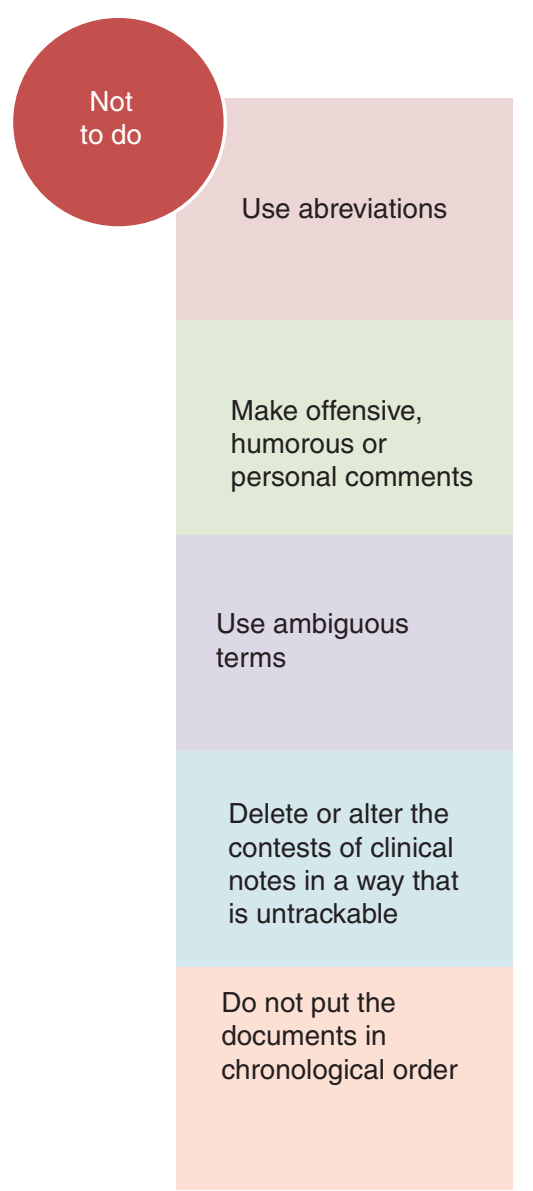

Use dated entires and write clear, accurate and legible notes

Use structured note (i.e. SOAP:

Subjective,

Objective,

Assessment and Plan)

Make records at the same time as the events you are recording or as soon as possible afterwards Make objective

Report anyoral communications (phone call, person conversation, etc) and subsequent actions

Do not forget informed consent Report anynoncompliance

Document ojections regarding care or case management

Medication allergies and adverse reactions are prominently noted in the record

Do not put diagnostic and laboratory reports into the record, if they were not reviewed by a pracitioner 
Table 17.10 Risk factors for falls in hospitalized patients [90]

\begin{tabular}{l}
\hline Age $>85$ years \\
\hline Male sex \\
\hline Recent fall \\
\hline Gait instability \\
\hline Agitation and/or confusion \\
\hline New urinary incontinence or frequency \\
\hline $\begin{array}{l}\text { Adverse drug reactions (especially with psychotropic } \\
\text { drugs) }\end{array}$ \\
$\begin{array}{l}\text { Neurocardiovascular instability (usually orthostatic } \\
\text { hypotension) }\end{array}$
\end{tabular}

Table 17.11 External and internal factors associated with falls [182]

\begin{tabular}{|c|c|}
\hline External factors & Internal factors \\
\hline Prior falls & Physical restraint \\
\hline Visual impairment & Unsuitable footwear \\
\hline Stroke & $\begin{array}{l}\text { Unsuitable ambulation } \\
\text { aids }\end{array}$ \\
\hline $\begin{array}{l}\text { Joint diseases (i.e., } \\
\text { arthritis/arthrosis) }\end{array}$ & $\begin{array}{l}\text { Environmental factors } \\
\text { (stairs, bathtub with no } \\
\text { support, poor lighting, } \\
\text { etc.) }\end{array}$ \\
\hline Orthostatic hypotension & \\
\hline $\begin{array}{l}\text { Acute diseases needing } \\
\text { hospitalization }\end{array}$ & \\
\hline Gait instability & \\
\hline Cognitive impairment & \\
\hline Urinary incontinence & \\
\hline $\begin{array}{l}\text { Drugs (impacting on } \\
\text { blood pressure, glycemia, } \\
\text { and gait) }\end{array}$ & \\
\hline
\end{tabular}

medications (Table 17.12) or health problems increasing the risk of falls, unsuitable footwear, and visual impairment. There is a high-quality evidence that multicomponent interventions can reduce risk for in-hospital falls by as much as $30 \%$ [91]. The optimal bundle is not clearly defined but relevant components are: patients risk assessment, patient and staff education, bedside signs and wristband alerts, footwear advice, scheduled and supervised toileting, and medication review [91]. In particular, patients' education should include exhaustive oral and written information to patients/caregivers - taking into consideration the patient's ability to understand and retain this information - about (1) patient's risk factors for falls; (2) how to call the nurse as well as when to ask for help before moving from or around the bed; (3) when and how to raise bed rails; (4) other interventions aimed at addressing individual risk factors.

Harms due to interventions have not been studied systematically, but they may include an increased use of restraints and sedatives and decreased patients' mobilization [91].

Key factors for a successful implementation of such multicomponent interventions include: leadership support, engagement of frontline in the design of the intervention, multidisciplinary committee, pilot-testing the intervention, and changing nihilistic opinions about falls [91].

Wandering. It refers to two different, sometimes associated, behaviors: (1) the tendency of nursing home residents or hospital inpatients to persistently walk, spatial disorientation, or a combination of both [92]; (2) a situation in which a subject with dementia has become lost in the community. Although not all subjects with cognitive impairment exhibit wandering behavior, all are at risk for wandering away from the care setting and becoming lost [93].

The first measure to prevent wandering consists of an accurate assessment of patient's diseases impairing cognition such as Alzheimer's disease, fronto-temporal dementia, Lewy body disease, multi-infarct dementia, and delirium, on admission. In such cases, supervision is pivotal to reduce wandering-related problems [94] and should allow an immediate identification of patients at risk (e.g. through colored wristbands, armbands, or gowns), strategies providing an intensive surveillance (i.e. rooms close to the nursing station so that can be easily controlled by nurses and patients cannot go out without passing through it), and engagement of family members. This latter can play an important role during hospitalization as a familiar voice or face can decrease fear and agitation of the patients, thus reducing the patient's willing of wandering. Other strategies may include the avoidance of rooms near elevators, stairs, or exit doors as patients with cognitive impairment tend to respond to what they see around them. Placing clothes, shoes, and suitcases out of the patient's view can help as well. Finally, electronic monitoring could represent a big help, installed in the 
Table 17.12 Drugs increasing the risk of falls [182]

\begin{tabular}{l|l|l|l}
\hline Drugs with sedative effect on the CNS & $\begin{array}{l}\text { Drugs acting on the CV } \\
\text { system }\end{array}$ & Laxatives & $\begin{array}{l}\text { Drugs causing } \\
\text { hypoglycemia }\end{array}$ \\
\hline Barbiturates & Diuretics & All types & Sulfonylureas \\
\hline Sleep-inducing/sedative drugs & Antiarrhythmic drugs & & Insulin \\
\cline { 1 - 1 } Tricyclic antidepressants & Vasodilators & & \\
\cline { 1 - 1 } Antipsychotics/neuroleptics & Cardiac glycosides & & \\
\cline { 1 - 1 } Antiparkinsonian agents & & & \\
\cline { 1 - 1 } Analgesics & & & \\
\hline Seizure medications & & & \\
\hline
\end{tabular}

$C N S$ central nervous system, $C V$ cardiovascular

division of a hospital or a nursing home and potentially linked to local law enforcement agency, such as in the Project Lifesaver technology (https://projectlifesaver.org/).

On the other end, inappropriate building organization, overworked and under-resourced system, and limited staff knowledge of these problems may represent risk factors for patients' wandering $[95,96]$.

Bed entrapment occurs when a patient is being caught, trapped, or entangled in the bed rails, mattress, or bed frame of a hospital bed [97]. Many health conditions can favor this event, such as cognitive and communication impairments, frailty, agitation, uncontrolled pain, uncontrolled body movements, and bladder and/ or bowel dysfunction. Healthcare professionals should perform a patient's evaluation to identify those at risk and monitor them by concentrating on the following elements: mental status, diseaserelated reasons for a reduced mobility capacity (obesity, neuromotor deficits), prior long bedridden period, risk of fall and fall-related injuries, urine/fecal incontinence, and the paradox effect of certain drugs.

In order to prevent this event, it is very important for all medical staff to familiarize with the areas of the bed where patients are most often entrapped (Fig. 17.4 and Table 17.13) [97]. These areas account for $80 \%$ of entrapment accidents occurring in the hospital. The US Food and Drug Administration (FDA) provided some precise indications for the sizes of the different parts of the bed aimed at reducing as much as possible these accidents. For instance, in order to avoid trunk, head, and neck to be blocked in the bottom part of the bed, mattresses should cover completely this area and resist to patient's movements and weight. Similarly, entrapment risks in the empty spaces between rails should be avoided. In Table 17.13, requirements for the size of the different bed areas are provided [98].

Aspiration pneumonia is considered as a continuum including community- and hospitalacquired pneumonias. However, data of inhospital aspiration pneumonias are lacking as solid diagnostic criteria are not available [99, 100].

An important step to face this dangerous complication is represented by the recognition of risk factors (Table 17.14). Indeed, patients presenting with many risk factors have a 9- to 13-fold increased risk of death and adverse outcomes [101]. Compared to patients with communityacquired pneumonia, those at risk for aspiration experienced a $70 \%$ increased risk for 1-year mortality, a 3-fold risk for recurrent pneumonia, and a 1.5-fold risk for re-hospitalization [101].

Since most of the elderly patients admitted to IM are assuming a long list of drugs, a great effort should be done to avoid sedatives, hypnotics, antipsychotic agents, and anti-histamines, if possible [102]. Additionally, patients with dysphagia, especially those affected by a previous stroke or a neurodegenerative disease, can benefit from speech and swallowing evaluation, before allowing feeding [103]. Oral feeding should always be preferred to enteral tube feeding using a mechanical soft diet with thickened liquids, avoiding pureed food and thin liquids. 


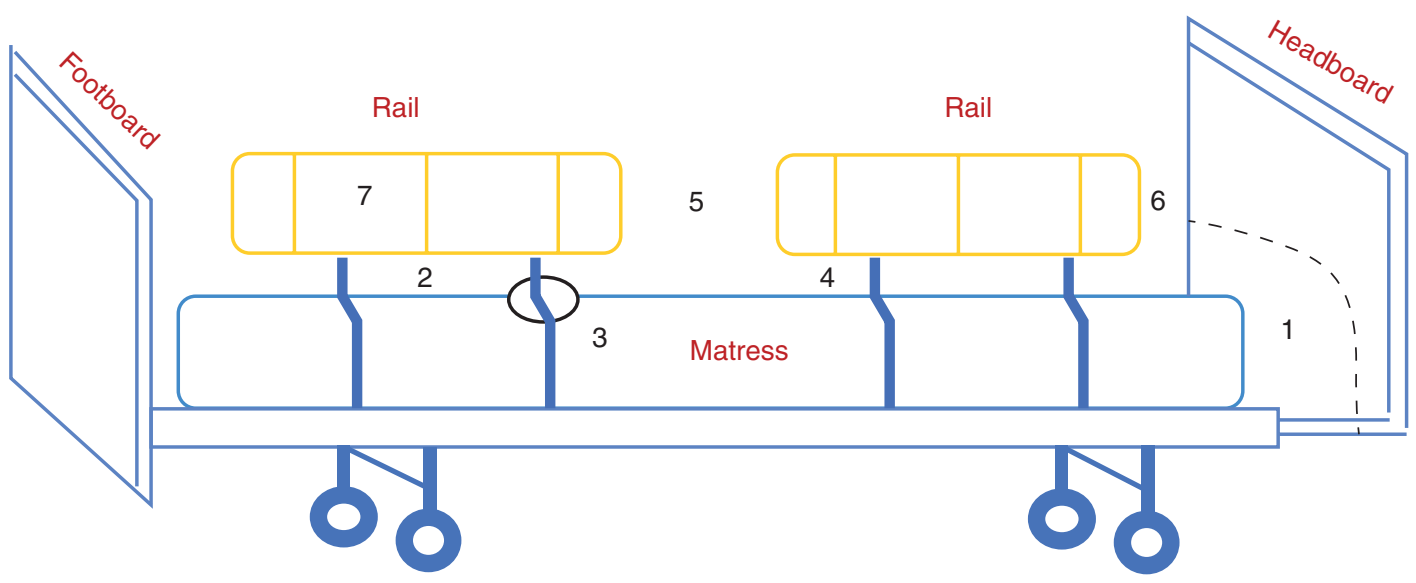

Fig. 17.4 Areas where patients are most often entrapped. Zone 1: between the headboard or footboard and the mattress; zone 2: under the rails; zone 3: between the rail and the mattress; zone 4 : under the ends of the rail; zone 5: between the 2 bed rails; zone 6 : between the end of the rail and the edge of the headboard or footboard; zone 7: within the rails [100]

Table 17.13 Areas of the bed at risk for entrapment and recommendations from the US Food and Drug Administration (FDA) [99]

\begin{tabular}{c|l|l}
\hline Zones & Definition & Recommendations \\
\hline Zone 1 & Any open space within the perimeter of the rail & $\begin{array}{l}\text { A loosened bar or rail can modify the size of the } \\
\text { space. } \\
\text { The recommended space is }<120 \text { mm (i.e., head } \\
\text { breadth) }\end{array}$ \\
\hline Zone 2 & $\begin{array}{l}\text { The space under the rail between a mattress } \\
\text { compressed by the weight of a patient's head and } \\
\text { the bottom edge of the rail at a location between } \\
\text { the rail supports or next to a single rail support } \\
\text { Zone 3 }\end{array}$ & $\begin{array}{l}\text { The space between the inner surface of the rail } \\
\text { and the mattress compressed by the weight of the } \\
\text { patient's head } \\
\text { The recommended space should be small enough to } \\
\text { avoid head entrapment, i.e., }<120 \text { mm }\end{array}$ \\
\hline Zone 4 & $\begin{array}{l}\text { The space growing between the mattress } \\
\text { This space should be small enough to avoid head } \\
\text { entrapment considering the mattress } \\
\text { compressibility and any lateral shift of the mattress } \\
\text { or rail, i.e., recommended space }<120 \text { mm }\end{array}$ \\
\hline the rail, at its end & $\begin{array}{l}\text { Consider mattress compressibility, lateral shift of } \\
\text { the mattress or rail, and degree of play from } \\
\text { loosened rails to avoid entrapment of the patient's } \\
\text { neck, i.e., recommended space }<60 \text { mm }\end{array}$ \\
\hline Zone 5 6 & $\begin{array}{l}\text { This area is occupied when partial length head } \\
\text { and foot side rails are used on the same side of } \\
\text { the bed } \\
\text { The space between the end of the rail and the side } \\
\text { edge of the headboard or footboard }\end{array}$ & $\begin{array}{l}\text { FDA recognizes these parts as at risk for } \\
\text { entrapment encouraging manufacturers to report } \\
\text { entrapment events at this area }\end{array}$ \\
\hline
\end{tabular}

However, when enteral feeding is unavoidable, patients should be positioned in a semi-recumbent and anti-Trendelenburg position to reduce the chance of gastric aspiration/regurgitation. In patients with dysphagia, it is helpful to consider a nutritional rehabilitation, during which swallowing exercises and early mobilization may reduce risks of aspiration and/or recurrences $[104,105]$. While the effectiveness of the nasogastric tube and the post-pyloric feeding is controversial, the use of angiotensin-converting enzyme inhibitors (as anti-hypertensive drug) and cilostazol (as an anti-platelet drug) acting on substance $\mathrm{P}$ and bradykinin and improving cough 
Table 17.14 Risk factors for aspiration pneumonia [103-105]

\begin{tabular}{|c|c|}
\hline \multirow[t]{4}{*}{ Impaired swallowing } & $\begin{array}{l}\text { Esophageal disease, including } \\
\text { dysphagia, head/neck cancer, } \\
\text { stricture, achalasia, } \\
\text { scleroderma, polymyositis }\end{array}$ \\
\hline & $\begin{array}{l}\text { Chronic obstructive } \\
\text { pulmonary disease }\end{array}$ \\
\hline & $\begin{array}{l}\text { Neurologic diseases, including } \\
\text { seizures, multiple sclerosis, } \\
\text { Parkinson's disease and } \\
\text { parkinsonism, stroke, } \\
\text { dementia }\end{array}$ \\
\hline & $\begin{array}{l}\text { Extubation from mechanical } \\
\text { ventilation }\end{array}$ \\
\hline \multirow[t]{4}{*}{$\begin{array}{l}\text { Impaired } \\
\text { consciousness }\end{array}$} & $\begin{array}{l}\text { Stroke or intracerebral } \\
\text { hemorrhage }\end{array}$ \\
\hline & Cardiac arrest \\
\hline & $\begin{array}{l}\text { Drug overdose and } \\
\text { medications, such as narcotic } \\
\text { agents, general anesthetic } \\
\text { agents, and some } \\
\text { antidepressant agents }\end{array}$ \\
\hline & Alcohol abuse \\
\hline \multirow[t]{3}{*}{$\begin{array}{l}\text { Increased amount of } \\
\text { gastric content } \\
\text { reaching the lungs }\end{array}$} & $\begin{array}{l}\text { Percutaneous enteral tube } \\
\text { feeding, especially when } \\
\text { associated with gastric } \\
\text { dysmotility and cognitive } \\
\text { impairment }\end{array}$ \\
\hline & Gastro-esophageal reflux \\
\hline & Gastroparesis \\
\hline \multirow{4}{*}{$\begin{array}{l}\text { Conditions impairing } \\
\text { the cough reflex }\end{array}$} & Stroke \\
\hline & Medications \\
\hline & Alcohol \\
\hline & $\begin{array}{l}\text { Degenerative neurologic } \\
\text { diseases }\end{array}$ \\
\hline \multirow[t]{3}{*}{ Others } & Male sex \\
\hline & Smoking \\
\hline & Diabetes mellitus \\
\hline
\end{tabular}

and swallowing reflexes showed more consisting results [106-108].

Oral hygiene may represent an important preventive action in non-ventilated patients: it has been demonstrated that chlorhexidine or mechanical oral cleaning reduce up to $60 \%$ risk of aspiration pneumonia [109]. However, it is important to remember that chlorhexidine can be toxic if aspirated into the lungs, especially by ventilated patients. The association of oral care to supplemental nutrition also demonstrated to lower aspiration pneumonia [110]. Anyway, a comprehensive oral care program (manual tooth, gum brushing, chlorhexidine mouthwashes, and upright positioning during feeding) evaluated in a cluster-randomized controlled trial conducted among nursing home residents showed a higher number of pneumonias/lower respiratory tract infections in the intervention group [111]. On the other hand, a short course $(\leq 24 \mathrm{~h})$ of prophylactic $\beta$-lactam antibiotics was shown to reduce the risk of aspiration around the time of endotracheal intubation [112].

Delirium is a neuropsychiatric syndrome characterized by altered consciousness and attention with cognitive, emotional, and behavioral symptoms. It occurs among hospitalized patients-mainly in elderly frail people - at a rate from $14 \%$ to $56 \%$ and increases morbidity and mortality [113]. In this condition, multiple risk factors have been identified so that suggested intervention is obviously multicomponent. Evidence shows that they are effective in preventing delirium onset in at-risk patients in a hospital setting, without significant associated harms but it is insufficient to identify which multicomponent interventions are the most beneficial, and which components within a program provide the most benefit $[114,115]$. The aim of primary prevention is to prevent physiological derangements by early mobilization, good hydration, sleep enhancement, family and caregiver involvement, in addition to physiotherapy and rehabilitation, as summarized in Table 17.15.

Since it is usually triggered by different factors, prevention strategies need to be reassessed during hospital stay [114].

Approaches including the education of nursing aides and caregivers, music therapy and psychotherapy gave no definitive results [114].

The main recently published studies on pharmacological approach are summarized in a review by $\mathrm{Oh}$ et al. [114]. In general, antipsychotic drugs did not demonstrate any clear benefit in preventing delirium [116], similarly to cholinesterase inhibitors, ketamine, melatonin, and melatonin-receptor agonist (ramelteon) [117, 118]. Hence, there is a lack of support in using drugs for prevention or treatment of delirium, especially when considered as a unique entity. 
Table 17.15 Multicomponent non-pharmacologic approaches to prevent delirium (adapted from [116])

\begin{tabular}{|c|c|}
\hline Type of approach & Description \\
\hline $\begin{array}{l}\text { Orientation and } \\
\text { therapeutic } \\
\text { activities }\end{array}$ & $\begin{array}{l}\text { - Provide adequate lighting, calendars, and clocks in order to help the patient orienting in the } \\
\text { space } \\
\text { - The patient should be oriented in the space and in the role of the healthcare providers } \\
\text { - Stimulate the patient with activities, such reminiscing, and favor the visits of family } \\
\text { members }\end{array}$ \\
\hline $\begin{array}{l}\text { Fluid } \\
\text { consumption }\end{array}$ & $\begin{array}{l}\text { - Patients should be encouraged to drink, eventually consider parenteral fluids } \\
\text { - It is helpful for the monitoring of fluid balance by personnel in patients with heart failure } \\
\text { or renal disease }\end{array}$ \\
\hline $\begin{array}{l}\text { Early } \\
\text { mobilization }\end{array}$ & $\begin{array}{l}\text { - Early postoperative mobilization should be encouraged as well as regular ambulation } \\
\text { through specific programs } \\
\text { - Patients should be involved in active exercises based on their capacities } \\
\text { - Walking aids (canes, walkers) must be always nearby }\end{array}$ \\
\hline $\begin{array}{l}\text { Feeding } \\
\text { assistance }\end{array}$ & $\begin{array}{l}\text { - General nutrition guidelines should be followed. If needed, an advice from a dietician can } \\
\text { be asked } \\
\text { - A proper fit of dentures must be provided }\end{array}$ \\
\hline $\begin{array}{l}\text { Vision and } \\
\text { hearing }\end{array}$ & $\begin{array}{l}\text { - Reversible cause of the impairment should be fixed } \\
\text { - Working hearing and visual aids must be available and used when needed }\end{array}$ \\
\hline $\begin{array}{l}\text { Sleep } \\
\text { enhancement }\end{array}$ & $\begin{array}{l}\text { - All medical or nursing procedures must be limited or avoided during sleep times } \\
\text { - Noise at night time must be avoided }\end{array}$ \\
\hline $\begin{array}{l}\text { Infection } \\
\text { prevention }\end{array}$ & $\begin{array}{l}\text { - Infections must be early recognized and treated } \\
\text { - Unnecessary catheterization must be avoided } \\
\text { - Infection-control procedures must be taken into consideration }\end{array}$ \\
\hline Pain management & $\begin{array}{l}\text { - It is always important to assess the pain, especially among those patients with } \\
\text { communication difficulties } \\
\text { - Pain must be monitored and managed in patients with known or suspected pain }\end{array}$ \\
\hline Hypoxia & - Hypoxia and oxygen saturation must always be monitored \\
\hline $\begin{array}{l}\text { Psychoactive } \\
\text { medication } \\
\text { protocol }\end{array}$ & $\begin{array}{l}\text { - The list of medications, including class and number, must always be checked and modified, } \\
\text { if needed }\end{array}$ \\
\hline
\end{tabular}

At the end, if non-pharmacological strategies were proved to be effective on delirium onset, no convincing impact was provided for hospital mortality, 6-month mortality, or institutionalization. As well, frailty, as a key predictor of outcomes, was not taken into consideration [119].

\subsubsection{Prevention of Healthcare- Associated Infections}

Healthcare-associated infections (HAIs) represent a relevant problem for hospitalized patients all over the world. Some 3.2 million patients in Europe suffer every year from HAIs, of which nearly one third is considered preventable [120].

Many preventive strategies may help in reducing the spreading of HAIs [121]. For instance, patients coming from the intensive care unit to
IM should be screened if they present with neutropenia, diarrhea, skin rashes, known communicable disease, or if they are known carriers of an epidemic bacterial strain. The recognition of risk factors, listed in Table 17.16 may help in reducing HAIs, too.

As hands are the most common vehicle for transmission of infections, hand hygiene is the single most effective measure to prevent the horizontal transmission of infections among hospitalized patients and healthcare personnel. In 2003, World Health Organization promoted a world challenge on this topic, introducing the five moments for hand hygiene, two before and three after approaching the patient: (1) before touching the patient in order to protect him/her from germs carried on healthcare personnel's hands; (2) before aseptic procedures to protect the patient against germs, including the patient's own ones; 
Table 17.16 Common risk factors increasing the risk of HAIs [122, 123]

\begin{tabular}{l|l}
\hline Patient-related & Age $>70$ years \\
\cline { 2 - 2 } & Shock \\
\cline { 2 - 2 } & Major trauma \\
\cline { 2 - 2 } Treatment-related & $\begin{array}{l}\text { Acute renal failure } \\
\text { Coma } \\
\text { Prior and/or prolonged antibiotic } \\
\text { therapy }\end{array}$ \\
\cline { 2 - 2 } & Mechanical ventilation \\
\cline { 2 - 2 } & $\begin{array}{l}\text { Drugs affecting the immune } \\
\text { system (steroids, chemotherapy) }\end{array}$ \\
\cline { 2 - 2 } & Indwelling catheters \\
\hline $\begin{array}{l}\text { Environment- } \\
\text { related }\end{array}$ & $\begin{array}{l}\text { Prolonged intensive care unit stay } \\
\text { (>3 days) }\end{array}$ \\
\hline
\end{tabular}

(3) after body fluid exposure; (4) after touching the patient; and (5) after touching the patient's surrounding (these three latter moments are intended to protect the personnel and the environment from the patient's germs) and two methods, with water and soap or alcohol-based solutions [122].

In addition, standard precautions include preventive measures that should always be used, irrespective of a patient's infection status. Sterile gloves should be worn after hand hygiene in case of sterile procedures or exposition to body fluids. It is important not to wear the same gloves when caring for more patients, remove them and wash hands after caring for a single patient. Wearing gown, mask, and eye protection/face shield is very important to avoid soiling clothing and skin during procedures potentially delivering body fluids [122].

In patients known or suspected to have airborne, contact or droplet infections (M. tuberculosis, $H$. influenzae, varicella zoster virus, herpes virus among others), additional precautions should be followed.

For airborne infections, isolation with negative-pressure ventilation is preferable. Additionally, all people entering the room, including visitors, must wear respiratory protections (such as the disposable $\mathrm{N}-95$ respirator mask).

For contact infections, single use patient-care equipment is recommended. If unavoidable, ade- quate cleaning and disinfection before using to another patient is mandatory. As well, the movements of the patients across different wards should be limited.

In droplet infections, the patient should be isolated and his/her movements limited, while respiratory protections must be worn when entering the isolation room. Additional specific strategies to prevent specific nosocomial infections have been reported by Mehta et al. [123].

Finally, environmental factors cannot be neglected. Adequate cleaning and disinfection are important, especially when considering the patient's closest surfaces, such as bedrails, bedside tables, doorknobs, and equipment. The frequency of cleaning should be as follows: surface cleaning twice weekly, floor cleaning 2-3 times/ day, and terminal cleaning after discharge or death. Central air-conditioning systems should ensure that air recirculates through appropriate filters (air should be filtered to $99 \%$ efficiency down to $5 \mu \mathrm{m}$ ). Isolation facility should include both negative- and positive-pressure ventilations. Alcohol gel dispensers should be positioned at the entry of every rooms and near entrance/exit for health operators, patients, and visitors.

\subsubsection{Prevention of Venous Thromboembolism}

The hospitalization for an acute condition is responsible for an eight-fold increase in the thrombotic risk and accounts for nearly $25 \%$ of all thromboembolic events [124]. However, risk stratification of patients admitted to IM is often complicated by their high heterogeneity [125, 126]. For this purpose, the Padua Prediction Score has been implemented and validated by Prandoni et al. [126]. It includes 11 thrombotic risk factors and identifies patients at high or low risk for venous thromboembolism (VTE) (Table 17.17). Patients with a score $<4$ (nearly $60 \%$ of the patients) are at low risk, while those with a risk score $\geq 4$ (nearly $40 \%$ ) have a high risk. Indeed, in the 3-month follow-up period, the incidence of VTE without any prophylaxis in the low-risk group was $0.3 \%$, while the incidence in the high- 
Table 17.17 The Padua Prediction Score [127]

\begin{tabular}{l|l}
\hline Baseline characteristics & Score \\
\hline Active cancer $^{\mathrm{a}}$ & 3 \\
\hline $\begin{array}{l}\text { Previous venous thromboembolism (excluding } \\
\text { superficial vein thrombosis) }\end{array}$ & 3 \\
\hline Reduced mobility $^{\mathrm{b}}$ & 3 \\
\hline Already known thrombophilic condition $^{\mathrm{c}}$ & 3 \\
\hline Recent ( $\leq 1$ month) trauma and/or surgery & 2 \\
\hline Elderly age $\left(\geq 70\right.$ years) $^{\text {Heart and/or respiratory failure }}$ & 1 \\
\hline Acute myocardial infarction or ischemic stroke & 1 \\
\hline Acute infection and/or rheumatologic disorder & 1 \\
\hline Obesity (BMI $\geq 30)$ & 1 \\
\hline Ongoing hormonal treatment & 1 \\
\hline
\end{tabular}

aPatients with local or distant metastases and/or in whom chemotherapy or radiotherapy had been performed in the previous 6 months

'Bedrest with bathroom privileges (either due to patient's limitations or on physicians order) for at least 3 days ${ }^{\mathrm{c}}$ Defects of anti-thrombin, protein $\mathrm{C}$ or $\mathrm{S}$, factor V Leiden, G20210A prothrombin mutation, and antiphospholipid syndrome

risk group was 11\% (hazard ratio HR 32.0, 95\% confidence interval 4.1-251.0). Based on these findings, the Padua Prediction Score was recommended as a tool for the identification of high-risk patients requiring thromboprophylaxis [125]. Anyway, the hemorrhagic risk should also be considered. In the study by Prandoni et al., major or clinically relevant bleeding complications were found in $1.6 \%$ of high-risk patients receiving pharmacological prophylaxis although all bleeding complications were non-fatal [126]. In another study, active gastroduodenal ulcer, prior bleeding within 3 months, and low platelet count $(<50,000 /$ $\mathrm{mm}^{3}$ ) were recognized as the strongest independent risk factors for bleeding [127]. Other bleeding risk factors included age $>85$ years, male sex, hepatic or renal failure, intensive care unit stay, central venous catheter, rheumatic disease, and cancer. All these factors have been integrated in a score for bleeding risk stratification (IMPROVE score), highlighting that more than a half of the major bleeding events were experienced by patients with a score $\geq 7$ [127].

Combining thrombotic and hemorrhagic risk assessments, pharmacological and nonpharmacological measures can be adopted to safely reduce in-hospital VTE [128].
Current evidence is concordant in recognizing a similar efficacy of low-molecular-weight heparin (LMWH) and low-dose unfractionated heparin (LDUH) in patients hospitalized in the medical setting although LMWH is more likely to be associated with a lower risk of bleeding. Fondaparinux, the only selective inhibitor of factor Xa approved for the treatment and prevention of thrombosis, showed a similar performance compared to heparin both in terms of thromboprophylaxis and risk of bleeding [125]. For patients with an increased risk of bleeding, alternative treatments, such as graduated compression stockings, intermittent pneumatic compression, and venous foot pumps, all aiming at reducing venous stasis by inducing the movement of blood from superficial to deep veins through the perforator veins are recommended [125].

Since IM usually receives a great number of patients often showing particular features (elderly, obese or underweight people, impaired kidney function, cancer), these specific populations need different managements [129].

Elderly patients present differences in terms of pharmacokinetics and an increased risk of bleeding, compared to the general population [130]. Further, older patients ( $>80$ years) show a ten-fold risk increased risk for VTE compared to younger ones. Indeed, in the MEDENOX study, enoxaparin was greatly effective in reducing the risk of VTE in patients $>80$ years hospitalized in medical wards [131].

Obesity and overweight are recognized risk factors for VTE. The main concern is to modify or not the dosages to get the same efficacy in such conditions. A study conducted in a medical ward in the USA tested the $0.5 \mathrm{mg} / \mathrm{kg} /$ day enoxaparin dosage in obese patients showing its feasibility and efficacy and, at the same time, the absence of any bleeding event, symptomatic VTE, or dangerous thrombocytopenia [132]. Some differences arose in a study among patients undergoing bariatric surgery [133] underlining potential differences in terms of absorption among the different formulations of LMWH. For this reason, for obese patients, dosages may need to be modified according to the drug used. 
In patients with kidney disease, LMWH and fondaparinux clearance is reduced and a modification of the dosage is required. Usually, LMWH can be used at the dosage indicated for thromboprophylaxis with a limited risk of bioaccumulation in patients with kidney disease treated for a limited period of time [134]. LDUH can be a valid alternative in patients with advanced kidney disease. Prophylactic doses of fondaparinux must be reduced when kidney function is severely impaired: $1.5 \mathrm{mg}$ /day when estimated glomerular filtration rate (eGFR) is $20-50 \mathrm{~mL} / \mathrm{min} / 1.73 \mathrm{~m}^{2}$. Fondaparinux is not recommended when eGFR is below $20 \mathrm{~mL} / \mathrm{min} / 1.73 \mathrm{~m}^{2}$ [135].

Patients with active cancer are known to be at increased risk of arterial embolism and VTE as well as bleeding events. Although treated for a long time with LMWH, recently direct oral anticoagulants have been found to be effective in reducing the risk of VTE and arterial embolism in many large randomized clinical trials. With this regard, an exhaustive report on these therapeutic strategies can be found in a recent review by Mosarla et al. [136]. Direct oral anticoagulants, however, are not yet approved for the prophylaxis of venous thromboembolism in these patients, but only in secondary prevention.

\subsubsection{Prevention of Pressure Ulcers}

Complications from hospital-acquired pressure ulcers cause about 60,000 deaths and relevant morbidity and resources consumption every year in the USA. Diabetes, obesity, and older age are known risk factors [137].

Moderate-strength evidence suggests that implementing multicomponent initiatives for pressure ulcer prevention in acute and long-term care settings can improve processes of care and reduce pressure ulcer rates [137].

Interventions usually address impaired mobility and/or nutrition and/or skin health. Using support surfaces, regularly repositioning the patient, optimizing nutritional status, and moisturizing sacral skin help to prevent pressure ulcers, along with initial and periodic risk stratification and personalized care for high-risk individuals. Many different pressure ulcer risk assessment tools are used in clinical practice (i.e. Braden, Norton, Exton-Smith, Waterlow, Knoll, ...), but a recent Cochrane review was unable to suggest that the use of one tool over the others because of low or very low certainty of available evidence [138]. Multicomponent interventions typically include 3-5 evidence-based practices that "when performed collectively and reliably, have been proven to improve patient outcomes" [139]. Further, experts recommend to pay attention to organizational and care coordination components [140, 141]. Organizational components include selecting lead team membership, establishing policies and procedures, evaluating quality processes, educating staff, using skin champions, and communicating written care plans. Care coordination components include creating a culture of change and establishing regular meetings to facilitate communication, collegiality, and learning [137].

Key components of successful implementation efforts include: simplification and standardization of pressure ulcer-specific interventions and documentation, involvement of multidisciplinary teams and leadership, designated skin champions, ongoing staff education, and sustained audit and feedback [137].

\subsubsection{Clinical Monitoring by Early Warning Scores}

Many hospitalized patients experience vital signs deterioration before cardiac arrest, unanticipated intensive care unit admission or unexpected death [142, 143]. Indeed, one or more aberrant vital signs can be detected by nurses or physicians in $60 \%$ of cases before the adverse event [144]. A rapid recognition of these antecedents and an appropriate treatment can prevent further deterioration so avoiding the development of the adverse outcomes. Several studies suggest that the triad of (1) early detection, (2) timeliness of response, and (3) competency of the response is crucial for patient's outcomes [145-147]. According to these considerations, the use of the so-called early warning scores (EWS) has been widely implemented 
by hospitals to efficiently identify and treat patients who present with or develop acute illness [147, 148]. Although different and heterogeneous EWS exist, they are characterized by few key features. First, they require a systematic method to measure simple vital signs at the right intervals in all patients to recognize those with clinical deterioration. The assessment of vital signs need to be simple and usable by all healthcare professionals after an appropriate training. Second, clear definitions of the urgency and of the appropriate clinical response are necessary. The trigger for the clinical response should not be too sensitive in order to avoid alerts but it also should not be so insensitive that it never leads to system response activation [149]. In the EWS, the points for the final score are allocated for each physiologic parameter according to how much it deviates from a predefined normal range, so that a higher score corresponds to greater patient's deterioration. So, clinical response can be adapted in terms of urgency and provider's level of expertise, ranging from the increase of vital signs monitoring to the activation of rapid response team. The vital signs considered in each EWS typically include pulse rate, breathing rate, blood pressure, level of consciousness and temperature [150]. There is, however, variability in other parameters included (e.g. pain, level of respiratory support, urine, age), in weights assigned, and in thresholds for triggering the response. In Table 17.18, the chart of National Early Warning Score (NEWS) used in the UK is reported, as an example [151]. Another important issue to consider is the frequency of vital signs monitoring.
Ideally, it should be done frequently enough to identify patient's deterioration at a time that allows interventions to improve outcomes. There is no evidence that continuous surveillance has a positive effect on mortality [152, 153]. Moreover, although an increase in monitoring frequency leads to a higher detection of events, it is also associated with a rise in expense and workload [149]. Thus, it is necessary to find a balance between patient's safety and available resources. According to evidence, patients at low risk should be monitored at least twice daily, whereas an increase in assessment frequency is required when EWS raise [154]. The appropriate responses to EWS can be described with an escalation protocol, in which at every threshold corresponds an action (see Table 17.19). Providers at every level of the chain have to operate according to their competences and skills. They have also to call medical emergency team (MET) when it is indicated by the protocol. Several studies, however, reported omission to call MET in $25-42 \%$ of cases in which patients presented calling criteria $[155,156]$. Reasons for non-adherence to protocol include negative attitude toward MET, staffs' confidence in their own ability, fear to appear incompetent or of criticism by the MET [155-158]. Ongoing education and training in the use of EWS is essential for all healthcare staff involved in the assessment and monitoring of acutely ill patients. A standardized system, jointly to a diffuse knowledge of it, is essential to achieve the aim of a rapid recognition of patient's deterioration, an appropriate clinical response and a favorable outcome.

Table 17.18 National Early Warning Score (NEWS), adapted from [153]

\begin{tabular}{|c|c|c|c|c|c|c|c|}
\hline $\begin{array}{l}\text { Physiological } \\
\text { parameters }\end{array}$ & 3 & 2 & 1 & 0 & 1 & 2 & 3 \\
\hline Respiration rate & $\leq 8$ & & $9-11$ & $12-20$ & & $21-24$ & $\geq 25$ \\
\hline Oxygen saturation & $\leq 91$ & $92-93$ & $94-95$ & $\geq 96$ & & & \\
\hline $\begin{array}{l}\text { Any supplemental } \\
\text { oxygen }\end{array}$ & & Yes & & No & & & \\
\hline Temperature & $\leq 35.0$ & & $35.1-36.0$ & $36.1-38.0$ & $38.1-39.0$ & $\geq 39.1$ & \\
\hline $\begin{array}{l}\text { Systolic blood } \\
\text { pressure }\end{array}$ & $\leq 90$ & $91-100$ & $101-110$ & $111-219$ & & & $\geq 220$ \\
\hline Heart rate & $\leq 40$ & & $41-50$ & $51-90$ & $91-110$ & $111-130$ & $\geq 131$ \\
\hline $\begin{array}{l}\text { Level of } \\
\text { consciousness }\end{array}$ & & & & A & & & $\mathrm{V}, \mathrm{P}$ or $\mathrm{U}$ \\
\hline
\end{tabular}


Table 17.19 Clinical response to NEWS trigger, adapted from [153]

\begin{tabular}{|c|c|c|}
\hline NEWS & $\begin{array}{l}\text { Frequency of } \\
\text { monitoring }\end{array}$ & Clinical response \\
\hline 0 & $\begin{array}{l}\text { Minimum } 12 \\
\text { hourly }\end{array}$ & $\begin{array}{l}\text { Continue NEWS } \\
\text { monitoring }\end{array}$ \\
\hline $\begin{array}{l}1-4 \\
\text { Low risk }\end{array}$ & $\begin{array}{l}\text { Minimum } 6 \\
\text { hourly }\end{array}$ & $\begin{array}{l}\text { Registered nurse to } \\
\text { decide if increased } \\
\text { frequency of monitoring } \\
\text { and/or escalation of } \\
\text { clinical care is required }\end{array}$ \\
\hline $\begin{array}{l}5-6 \text { or } 3 \text { in } \\
1 \\
\text { parameter } \\
\text { Medium } \\
\text { risk }\end{array}$ & $\begin{array}{l}\text { Minimum } 1 \\
\text { hourly }\end{array}$ & $\begin{array}{l}\text { - Registered nurse to } \\
\text { urgently inform the } \\
\text { medical team caring for } \\
\text { the patient } \\
\text { - Urgent assessment } \\
\text { by a clinician with core } \\
\text { competencies to assess } \\
\text { acutely ill patients } \\
\text { - Clinical care in an } \\
\text { environment with } \\
\text { monitoring facilities }\end{array}$ \\
\hline $\begin{array}{l}7 \text { or more } \\
\text { High risk }\end{array}$ & $\begin{array}{l}\text { Continuous } \\
\text { monitoring }\end{array}$ & $\begin{array}{l}\text { - Registered nurse to } \\
\text { immediately inform the } \\
\text { medical team caring for } \\
\text { the patient } \\
\text { - Emergency } \\
\text { assessment by a clinical } \\
\text { team with critical care } \\
\text { competencies, which } \\
\text { also includes a } \\
\text { practitioner/s with } \\
\text { advanced airways skills } \\
\text { Intensive Unit Care }\end{array}$ \\
\hline
\end{tabular}

\subsubsection{Sepsis Bundles}

The mortality rate for severe sepsis and septic shock remains a major concern in clinical practice [159]. The Surviving Sepsis Campaign (SSC) is a joint collaboration of the Society of Critical Care Medicine and the European Society of Intensive Care Medicine created in 2002 to increase sepsis awareness, improve early diagnosis, increase the use of appropriate timely care, develop guidelines and spread them, in order to reduce morbidity and mortality for sepsis. Sepsis bundles were presented for the first time in the SSC Guideline for the management of severe sepsis and septic shock in 2004 [160]. They were created to bring guidelines key elements to clinicians' daily practice [161]. Indeed, a bundle is a small and straightforward set of evidence-based practices that, when performed altogether, have been proven to improve outcomes [162]. Hospitals that have successfully implemented sepsis bundles have consistently shown improved outcomes and reductions in healthcare spending [163]. Over the years, sepsis bundles have been revised according to most recent scientific evidence $[164,165]$. The most recent version is the hour-1 bundle, published in June 2018 [166]. Sepsis is a medical emergency. Early recognition and prompt management in the first hours after its development improve the survival [167]. Accordingly, the aim of hour- 1 bundle is to begin sepsis management and resuscitation immediately although some of the actions require more than $1 \mathrm{~h}$ to be completed.

The hour-1 bundle includes five key steps:

1. Measure lactate levels and re-measure if initial lactate is $>2 \mathrm{mmol} / \mathrm{L}$. Lactate is a surrogate for tissue perfusion measurement [168]. Lactate-guide resuscitation has been shown to reduce mortality in randomized control trials $[169,170]$. So that, if initial lactate is elevated ( $>2 \mathrm{mmol} / \mathrm{L}$ ), the measure should be repeated within $2-4 \mathrm{~h}$ and the treatment should be based on its values with the aim of normalizing lactate.

2. Obtain blood cultures prior to antibiotics administration (at least two sets, aerobic and anaerobic). If obtaining blood cultures is difficult, however, do not delay antibiotic treatment beginning. The identification of pathogens improve outcomes, but can be difficult to obtain after antimicrobial treatment for the rapid sterilization of cultures [171].

3. Administer broad-spectrum antibiotics. The antimicrobial treatment should be started empirically with one or more intravenous broad-spectrum antibiotics. Therapy should be narrowed once pathogen is identified.

4. Begin rapid administration of $30 \mathrm{~mL} / \mathrm{kg}$ of crystalloid fluids in case of hypotension or lactate $\geq 4 \mathrm{mmol} / \mathrm{L}$. Fluid resuscitation should be started immediately after the recognition of sepsis signs. The use of colloids did not show any clear benefit and it is, therefore, not recommended by guidelines. 
5. Administer vasopressor for hypotension during or after fluid resuscitation, in order to achieve a mean arterial pressure $\geq 65 \mathrm{mmHg}$. All these actions must be initiated within $1 \mathrm{~h}$ from "Time Zero," defined as the time of triage in the Emergency Department or, in case of sepsis presenting in another care location, from the earliest chart annotation consistent with elements of sepsis or septic shock.

A successful treatment of sepsis and septic shock require the collaboration of all healthcare professionals. The role of nurses is particularly important because they interact constantly with patients and they can provide early recognition of sepsis and implement a rapid clinical response [172]. Education programs on sepsis screening and hour-1 bundle should be strongly recommended for the entire medical staff. The website survivingsepsis.org provides resources and tools to improve sepsis knowledge.

\subsubsection{Safe Management of Outlier Patients}

"Outlier" or "out-lying hospital in-patient" is a patient who, is admitted wherever an unoccupied bed is, because of unavailability of hospital beds in his/her clinically appropriate ward [173, 174]. In such case, clinical management is on charge of physicians of the clinically appropriate ward (generally IM ward), but care is delivered by nursing staff of the hosting ward (often a surgical ward). Outliers phenomenon involve commonly medical patients in countries with a public health system that faced hospital beds cuts, over the last decades. Outliers represent about $7-8 \%$ of all admissions every year [173]. They are the other neglected face of hospital overcrowding. From a patient safety point of view, they have been defined, according to Reason's Swiss cheese model, "a latent condition which may underpin adverse events." Identification errors, missed or delayed diagnosis and treatment, HAIs, delirium and falls could be amplified by outlier status, due to delay between admission and medical evaluation, discontinuity of care, errors or delay in tests request/execution, inadequate communication between ward-teams, less familiarity with monitoring and treatment by hosting team [174]. Despite their compelling nature, they have been poorly studied. Available evidence shows a trend to increase in-hospital mortality and hospital readmission, but presents many serious limitations [174]. Also evidence-based guidelines to safely manage outliers clinical risks are still lacking. Only some bed management policies, formulated mainly by NHS Trusts across the UK [175, 176] contain some indications to ensure safety, dignity, and duty of care for both patients and staff involved in the care of outliers. As an example, that from Portsmouth Hospitals NHS trust recognizes that the best choice is not to admit to off-service units, but when unavoidable, the risk for patients and staff need to be minimized. It recommends not to admit to off-service units directly from emergency department or acute medicine, except in rare cases. It prescribes to rate patients' suitability to be moved to other units, with a score (RAG) based on clinical and mental health needs, level of acuity and dependency and clinical capability of the receiving area. RAG must be assessed within $24 \mathrm{~h}$ from admission and reviewed every day. Further, outliers must be placed in the same level of care and treatment that they would receive if cared in their appropriate unit. They must be reviewed by medical and/or nursing teams from their clinically appropriate unit daily. Patient treatment plans must be updated including pending investigations and discharge plans carefully documented in the patient's health records. The number of bed moves during each patient's stay must be minimized. Relatives must be informed of every movement and patients must be involved in decision by signing an informed consent [177].

\subsection{Case Studies}

\subsubsection{Case Study 1}

Female, 36 y-o, immigrant, unemployed, living with her husband and a $6 \mathrm{y}-\mathrm{o}$ daughter. Access to Emergency Room (ER) at 5.30 p.m. for left flank pain and hematuria. Previous history of kidney 
stones. Giordano's test positive. Her general practitioner suggests hospital admission for alcohol withdrawal. Blood tests reveal increased neutrophils, c-reactive protein and transaminases; abdominal US scan shows left hydro-nephrosis but not signs of liver damage. After $5 \mathrm{~h}$, she is discharged with a diagnosis of hypertransaminasemia in chronic alcohol abuse. Left renal colic. ER physician says she preferred go back home to fix her daughter tonight and will come back tomorrow. Twelve hours later, she is back to ER. ER physicians writes: "the patient comes back for left flank pain”. Her general practitioner contacted social and psychiatric services. She remains in the ER until 5.00 p.m. without clinical nor laboratorial re-evaluation. Then she is admitted to a medical ward for bilateral renal colic and alcohol abuse. At 9 p.m. onset of worsening psychomotor agitation, treated by diazepam, gabapentin, vitamin B6, and fluids. At 8 a.m., she receives the first dose of antibiotics (i.v. piperacillin/tazobactam). At 9 a.m., nurse reports hypotension (90/60 $\mathrm{mmHg}$ ) and low peripheral oxygen saturation ( $92 \%$ room air); instead physician writes in medical record "inappropriate admission," withdrawal syndrome in chronic alcohol abuse. At 2 p.m., morning shift physician hands off the patient saying she is going home because she rejects treatment. During the afternoon, psychomotor agitation worsens so that the treatment with fluids and oxygen is compromised and relatives are asked to provide assistance to her. She receives multiple administration of i.v. midazolam. At 8 p.m., she has cardiorespiratory arrest. She is resuscitated and transferred to intensive care unit. A diagnosis of post-anoxic coma and septic shock by Escherichia coli is made and the patient dies after 20 days without ever regaining consciousness.

\subsubsection{Case Study 2}

A 78-year-old man, previous gastric ulcer and depression, affected by metastatic colon cancer in home palliative care, was admitted to IM ward on December 27th at 1.00 a.m., after rejecting hospice admission to die at home, just the day before. He was on transdermal and sublingual (breakthrough cancer pain) opioids, intravenous opioids, haloperidol, and hyoscine (elastomeric pump). He died about $20 \mathrm{~h}$ later. Ten days after, his wife and son made a claim for bad assistance. They complained that their relative was removed from sedation, so he was awake in the grip of its devastating pains; his pain was not asked or evaluated; no painkillers were given. They were told by the nurses: "We can't do more than that. Sedation is a matter of anesthesia." On the contrary, electronic medical record reported that patient was unresponsive to any stimulus since admission; sedation was not interrupted; intravenous opioids dose was progressively increased; pain evaluation was frequent and pain control was achieved in few time. Health operators declared also that his relatives were allowed to stay with him until the end and any their desire such as music listening was satisfied. Why so different perceptions?

Despite of technical expertise and some human compassion, audit disclosed communication failure, and inappropriate setting (acute care ward). First of all, ward team missed medication and care plan recognition with palliative doctors, and, most of all, it did not effectively take care of family concerns and expectations. Health operators did not explore family feelings, did not provide frequent and punctual information about what was done and reassurance about their beloved clinical condition, in particular unconsciousness.

\subsubsection{Epicrisis and Recommendations}

\subsubsection{Clinical Case 1}

1. Be aware of Medical mimics or secondary psychoses, medical conditions mimicking psychiatric disorders, especially in patients with previous psychiatric history.

2. Remember that infections, trauma, autoimmune, metabolic, neurological diseases, and pharmacological withdrawal can present with psychiatric symptoms, from psychomotor agitation to anxiety, depression, dementia, or apathy. 
3. Think about medical mimics in case of: patient over 40 years and no previous psychiatric history, no history of similar symptoms or worsening of previous symptoms, family concern, chronic comorbidities, history of head injury, change in headache pattern, worsening after antipsychotics or anxiolytics, history of changing psychiatric diagnoses over time, difficult or unlikable patient, polypharmacy, abnormal autonomic signs, visual disturbance, visual, olfactory or tactile hallucinations, nystagmus, illusions, speech deficit, abnormal body movement [178].

4. Have a complete medical and psychiatric history, an exhaustive review of systems to identify symptoms/signs suggestive of medical diseases, review of any drug prescription, over-the-counter and alternative medications included, a careful mental status examination, diagnostic tests for diseases known to mimic psychiatric disorders (look for head trauma, syphilis or hypothyroidism, glucose or electrolyte or blood gases alterations, sepsis, etc.)

5. Avoid incorrect assumptions (patient triaged as psychiatric, is psychiatric; patient with psychiatric history, has only psychiatric disease; young patients suffer from functional disorders; abnormal vital signs are due to mental/ emotional state) and pitfalls (cursory history from limited sources, incomplete review of system, incomplete physical and neuropsychiatric exam, failure to review medications) [179].

\subsubsection{Clinical Case 2}

- In end-of-life care, ensure skillful communication with patients and families.

- Define and share with patient and/or family realistic goals of care.

- Pay attention to understanding the patient's and family's concerns besides competent symptom management [180].

Acknowledgments The authors gratefully thank Roberto Nardi, MD for his very helpful and accurate review and Julia Bashore, BS for the language check of this chapter.

\section{References}

1. Schimmel EM. The hazards of hospitalization. Ann Intern Med. 1964;60:100-10. https://doi. org/10.7326/0003-4819-60-1-100.

2. Barr DP. Hazards of modern diagnosis and therapy: the price we pay. J Am Med Assoc. 1955;159(15):1452-6.

3. Moser RH. Diseases of medical progress. N Engl J Med. 1956;255(13):606-14. https://doi.org/10.1056/ NEJM195609272551306.

4. Steel K, Gertman PM, Crescenzi C, Anderson J. Iatrogenic illness on a general medical service at a university hospital. $\mathrm{N}$ Engl $\mathrm{J}$ Med. 1981;304(11):638-42. https://doi.org/10.1056/ NEJM198103123041104.

5. Brennan TA, Leape LL, Laird NM, Hebert L, Localio AR, Lawthers AG, et al. Incidence of adverse events and negligence in hospitalized patients. Results of the Harvard Medical Practice Study I. N Engl J Med. 1991;324(6):370-6. https://doi.org/10.1056/ NEJM199102073240604.

6. Wilson RM, Runciman WB, Gibberd RW, Harrison BT, Newby L, Hamilton JD. The quality in Australian health care study. Med J Aust. 1995;163(9):458-71.

7. Vincent C, Neale G, Woloshynowych M. Adverse events in British hospitals: preliminary retrospective record review. BMJ. 2001;322(7285):517-9. https:// doi.org/10.1136/bmj.322.7285.517.

8. Thomas EJ, Studdert DM, Burstin HR, Orav EJ, Zeena T, Williams EJ, et al. Incidence and types of adverse events and negligent care in Utah and Colorado. Med Care. 2000;38(3):261-71. https:// doi.org/10.1097/00005650-200003000-00003.

9. Madeira S, Melo M, Porto J, Monteiro S, Pereira de Moura JM, Alexandrino MB, et al. The diseases we cause: iatrogenic illness in a department of internal medicine. Eur J Intern Med. 2007;18(5):391-9. https://doi.org/10.1016/j.ejim.2006.12.009.

10. Bellido D, Leon A, Manas MD, Marchan E, Esquinas G, Ros J. Adverse events in an internal medicine: a prospective study. Rev Calid Asist. 2017;32(5):2968. https://doi.org/10.1016/j.cali.2017.02.003.

11. Collopy BT. Adverse events in the 'medical' ward. J Qual Clin Pract. 2001;21(3):49.

12. Baker GR, Norton PG, Flintoft V, Blais R, Brown A, Cox J, et al. The Canadian adverse events study: the incidence of adverse events among hospital patients in Canada. CMAJ. 2004;170(11):1678-86.

13. Zegers M, de Bruijne MC, Wagner C, Hoonhout LH, Waaijman R, Smits M, et al. Adverse events and potentially preventable deaths in Dutch hospitals: results of a retrospective patient record review study. Qual Saf Health Care. 2009;18(4):297-302. https:// doi.org/10.1136/qshc.2007.025924.

14. Grober ED, Bohnen JM. Defining medical error. Can J Surg. 2005;48(1):39-44.

15. Nendaz M, Perrier A. Diagnostic errors and flaws in clinical reasoning: mechanisms and prevention 
in practice. Swiss Med Wkly. 2012;142:w13706. https://doi.org/10.4414/smw.2012.13706.

16. Boostani K, Noshad H, Farnood F, Rezaee H, Teimouri S, Entezari-Maleki T, et al. Detection and management of common medication errors in internal medicine wards: impact on medication costs and patient care. Adv Pharm Bull. 2019;9(1):174-9. https://doi.org/10.15171/apb.2019.020.

17. Haque M, Sartelli M, McKimm J, Abu Bakar M. Health care-associated infections-an overview. Infect Drug Resist. 2018;11:2321-33. https://doi. org/10.2147/IDR.S177247.

18. ECRI. Institute Patient Safety Organization's deep dive: patient identification executive summary. 2016. https://www.ecri.org/Resources/Whitepapers_and_ reports/PSO\%20Deep\%20Dives/Deep\%20Dive_ PT_ID_2016_exec\%20summary.pdf. Last accessed 25 Oct 2019.

19. Scott IA. Errors in clinical reasoning: causes and remedial strategies. BMJ. 2009;338:b1860. https:// doi.org/10.1136/bmj.b1860.

20. Committee on Diagnostic Error in Health Care, Board on Health Care Services, Institute of Medicine, The National Academies of Sciences E, Medicine. Overview of diagnostic error in health care. 2015.

21. Wilson RM, Harrison BT, Gibberd RW, Hamilton JD. An analysis of the causes of adverse events from the quality in Australian health care study. Med J Aust. 1999;170(9):411-5.

22. Schiff GD, Hasan O, Kim S, Abrams R, Cosby K, Lambert BL, et al. Diagnostic error in medicine: analysis of 583 physician-reported errors. Arch Intern Med. 2009;169(20):1881-7. https://doi. org/10.1001/archinternmed.2009.333.

23. Ely JW, Levinson W, Elder NC, Mainous AG 3rd, Vinson DC. Perceived causes of family physicians' errors. J Fam Pract. 1995;40(4):337-44.

24. Podbregar M, Voga G, Krivec B, Skale R, Pareznik $\mathrm{R}$, Gabrscek L. Should we confirm our clinical diagnostic certainty by autopsies? Intensive Care Med. 2001;27(11):1750-5. https://doi.org/10.1007/ s00134-001-1129-x.

25. Graber ML, Franklin N, Gordon R. Diagnostic error in internal medicine. Arch Intern Med. 2005;165(13):1493-9. https://doi.org/10.1001/ archinte.165.13.1493.

26. Phua DH, Tan NC. Cognitive aspect of diagnostic errors. Ann Acad Med Singap. 2013;42(1):33-41.

27. Clinical Excellence Commission. Diagnostic error: learning resource for clinicians. 2015. http:// www.cec.health.nsw.gov.au/__data/assets/pdf_ file/0005/305843/6.Diagnostic-Error-Learningresource-for-clinicians.pdf. Last accessed 25 Oct 2019.

28. Health Research \& Educational Trust. Improving diagnosis in medicine change package. 2018. http:// www.hret-hiin.org/. Last accessed 25 Oct 2019.

29. Graber ML. Educational strategies to reduce diagnostic error: can you teach this stuff? Adv Health Sci Educ Theory Pract. 2009;14(Suppl 1):63-9. https:// doi.org/10.1007/s10459-009-9178-y.
30. Riches N, Panagioti M, Alam R, Cheraghi-Sohi S, Campbell S, Esmail A, et al. The effectiveness of electronic differential diagnoses (DDX) generators: a systematic review and meta-analysis. PLoS One. 2016;11(3):e0148991. https://doi.org/10.1371/journal.pone.0148991.

31. Croskerry P, Singhal G, Mamede S. Cognitive debiasing 1: origins of bias and theory of debiasing. BMJ Qual Saf. 2013;22(Suppl 2):ii58-64. https://doi. org/10.1136/bmjqs-2012-001712.

32. Clinical Excellence Commission. Take 2-think, do Project. 2015. http://www.cec.health.nsw.gov.au/_ data/assets/pdf_file/0008/305846/3.Take-2-ThinkDo-Information-for-Clinicians.pdf. Last accessed 28 Oct 2019.

33. Graber ML, Kissam S, Payne VL, Meyer AN, Sorensen A, Lenfestey N, et al. Cognitive interventions to reduce diagnostic error: a narrative review. BMJ Qual Saf. 2012;21(7):535-57. https://doi. org/10.1136/bmjqs-2011-000149.

34. National Coordinating Council for Medication Error Reporting and Prevention (NCC MERP). Taxonomy of medication errors. 1998. https://www.nccmerp. org/sites/default/files/taxonomy2001-07-31.pdf. Last accessed 25 Oct 2019.

35. Wittich CM, Burkle CM, Lanier WL. Medication errors: an overview for clinicians. Mayo Clin Proc. 2014;89(8):1116-25. https://doi.org/10.1016/j. mayocp.2014.05.007.

36. Elliott R, Camacho E, Campbell F, Jankovic D, Martyn St James M, Kaltenthaler E, Wong R, Sculpher M, Faria R. Prevalence and economic burden of medication errors in the NHS in England. Rapid evidence synthesis and economic analysis of the prevalence and burden of medication error in the UK. Policy Research Unit in Economic Evaluation of Health and Care Interventions. Universities of Sheffield and York; 2018.

37. Jha AK, Larizgoitia I, Audera-Lopez C, PrasopaPlaizier N, Waters H, Bates DW. The global burden of unsafe medical care: analytic modelling of observational studies. BMJ Qual Saf. 2013;22(10):809-15. https://doi.org/10.1136/ bmjqs-2012-001748.

38. Bates DW, Boyle DL, Vander Vliet MB, Schneider J, Leape L. Relationship between medication errors and adverse drug events. J Gen Intern Med. 1995;10(4):199-205. https://doi.org/10.1007/ bf02600255.

39. Cullen DJ, Sweitzer BJ, Bates DW, Burdick E, Edmondson A, Leape LL. Preventable adverse drug events in hospitalized patients: a comparative study of intensive care and general care units. Crit Care Med. 1997;25(8):1289-97. https://doi. org/10.1097/00003246-199708000-00014.

40. Jimenez Munioz AB, Muino Miguez A, Rodriguez Perez MP, Escribano MD, Duran Garcia ME, Sanjurjo SM. Medication error prevalence. Int $\mathrm{J}$ Health Care Qual Assur. 2010;23(3):328-38. https:// doi.org/10.1108/09526861011029389.

41. Leape LL, Bates DW, Cullen DJ, Cooper J, Demonaco HJ, Gallivan T, et al. Systems analysis of 
adverse drug events. ADE Prevention Study Group. JAMA. 1995;274(1):35-43.

42. Kohn LT, Corrigan J, Donaldson MS, editors. To err is human: building a safer health system. Washington, DC: National Academy Press; 2000.

43. Bedell SE, Jabbour S, Goldberg R, Glaser H, Gobble $\mathrm{S}$, Young-Xu Y, et al. Discrepancies in the use of medications: their extent and predictors in an outpatient practice. Arch Intern Med. 2000;160(14):212934. https://doi.org/10.1001/archinte.160.14.2129.

44. Bell CM, Brener SS, Gunraj N, Huo C, Bierman AS, Scales DC, et al. Association of ICU or hospital admission with unintentional discontinuation of medications for chronic diseases. JAMA. 2011;306(8):840-7. https://doi.org/10.1001/ jama.2011.1206.

45. Coleman EA, Smith JD, Raha D, Min SJ. Posthospital medication discrepancies: prevalence and contributing factors. Arch Intern Med. 2005;165(16):1842-7. https://doi.org/10.1001/archinte.165.16.1842.

46. Salanitro AH, Osborn CY, Schnipper JL, Roumie CL, Labonville S, Johnson DC, et al. Effect of patient- and medication-related factors on inpatient medication reconciliation errors. J Gen Intern Med. 2012;27(8):924-32. https://doi.org/10.1007/ s11606-012-2003-y.

47. Dornan T et al. An in-depth investigation into causes of prescribing errors by foundation trainees in relation to their medical education: EQUIP study. http:// www.gmcuk.org/FINAL_Report_prevalence_and_ causes_of_prescribing_errors.pdf_28935150.pdf. Last accessed 25 Oct 2019.

48. Ryan C, Ross S, Davey P, Duncan EM, Francis JJ, Fielding S, et al. Prevalence and causes of prescribing errors: the PRescribing Outcomes for Trainee Doctors Engaged in Clinical Training (PROTECT) study. PLoS One. 2014;9(1):e79802. https://doi. org/10.1371/journal.pone.0079802.

49. Aspden P, Wolcott J, Bootman JL, Cronenwett LR, editors. Preventing medication errors: quality chasm series. Washington, DC: Institute of Medicine of the National Academies; 2007. https://www.nap.edu/ read/11623/chapter/1. Last accessed 25 Oct 2019.

50. Medication safety in high-risk situations. Geneva: World Health Organization; 2019 (WHO/UHC/ SDS/2019.10). Licence: CC BY-NC-SA 3.0 IGO.

51. Masnoon N, Shakib S, Kalisch-Ellett L, Caughey GE. What is polypharmacy? A systematic review of definitions. BMC Geriatr. 2017;17(1):230. https:// doi.org/10.1186/s12877-017-0621-2.

52. Dupouy J, Moulis G, Tubery M, Ecoiffier M, Sommet A, Poutrain JC, et al. Which adverse events are related to health care during hospitalization in elderly inpatients? Int J Med Sci. 2013;10(9):122430. https://doi.org/10.7150/ijms.6640.

53. Medication safety in transitions of care. Geneva: World Health Organization; 2019 (WHO/UHC/ SDS/2019.9). Licence: CC BY-NC-SA 3.0 IGO.

54. Salanitro AH, Kripalani S, Resnic J, Mueller SK, Wetterneck TB, Haynes KT, et al. Rationale and design of the multicenter medication reconcili- ation quality improvement study (MARQUIS). BMC Health Serv Res. 2013;13:230. https://doi. org/10.1186/1472-6963-13-230.

55. Nuckols TK, Smith-Spangler C, Morton SC, Asch SM, Patel VM, Anderson LJ, et al. The effectiveness of computerized order entry at reducing preventable adverse drug events and medication errors in hospital settings: a systematic review and meta-analysis. Syst Rev. 2014;3:56. https://doi. org/10.1186/2046-4053-3-56.

56. Poon EG, Keohane CA, Yoon CS, Ditmore M, Bane A, Levtzion-Korach O, et al. Effect of bar-code technology on the safety of medication administration. N Engl J Med. 2010;362(18):1698-707. https://doi. org/10.1056/NEJMsa0907115.

57. Kwan JL, Lo L, Sampson M, Shojania KG. Medication reconciliation during transitions of care as a patient safety strategy: a systematic review. Ann Intern Med. 2013;158(5 Pt 2):397-403. https://doi. org/10.7326/0003-4819-158-5-201303051-00006.

58. Lamont T, Luettel D, Scarpello J, O'Driscoll $\mathrm{BR}$, Connew S. Improving the safety of oxygen therapy in hospitals: summary of a safety report from the National Patient Safety Agency. BMJ. 2010;340:c187. https://doi.org/10.1136/bmj.c187.

59. Risk of severe harm and death from unintentional interruption of non-invasive ventilation. https:// www.england.nhs.uk/wp-content/uploads/2015/02/ psa-niv.pdf. Last accessed 28 Oct 2019.

60. Safety in respiratory care: a guide to JCAHO requirements. http://hcpro.com/content/32186.pdf. Last accessed 28 Oct 2019.

61. Davidson AC, Banham S, Elliott M, Kennedy D, Gelder C, Glossop A, et al. BTS/ICS guideline for the ventilatory management of acute hypercapnic respiratory failure in adults. Thorax. 2016;71(Suppl 2):ii1-35. https://doi.org/10.1136/ thoraxjnl-2015-208209.

62. National Safety Standards for Invasive Procedures (NatSSIPS). https://improvement.nhs.uk/documents/923/natssips-safety-standards.pdf. Last accessed 28 Oct 2019.

63. Gordon CE, Feller-Kopman D, Balk EM, Smetana GW. Pneumothorax following thoracentesis: a systematic review and meta-analysis. Arch Intern Med. 2010;170(4):332-9. https://doi.org/10.1001/ archinternmed.2009.548.

64. MacMillan TE, Wu RC, Morra D. Quality of bedside procedures performed on general medical inpatients: can we do better? Can J Gen Intern Med. 2014;9(1):17-20.

65. Hewett R, Counsell C. Documentation of cerebrospinal fluid opening pressure and other important aspects of lumbar puncture in acute headache. Int J Clin Pract. 2010;64(7):930-5. https://doi. org/10.1111/j.1742-1241.2010.02415.x.

66. Daniels CE, Ryu JH. Improving the safety of thoracentesis. Curr Opin Pulm Med. 2011;17(4):232-6. https://doi.org/10.1097/MCP.0b013e328345160b.

67. Wigton RS, Alguire P, American College of Physicians. The declining number and variety of 
procedures done by general internists: a resurvey of members of the American College of Physicians. Ann Intern Med. 2007;146(5):355-60. https://doi. org/10.7326/0003-4819-146-5-200703060-00007.

68. Wickstrom GC, Kolar MM, Keyserling TC, Kelley DK, Xie SX, Bognar BA, et al. Confidence of graduating internal medicine residents to perform ambulatory procedures. J Gen Intern Med. 2000;15(6):361-5. https://doi. org/10.1046/j.1525-1497.2000.04118.x.

69. Sevdalis N, Arora S. Safety standards for invasive procedures. BMJ. 2016;352:i1121. https://doi. org/10.1136/bmj.i1121.

70. DeBiasi EM, Puchalski J. Thoracentesis: state-of-theart in procedural safety, patient outcomes, and physiologic impact. PLEURA. 2016;3:2373997516646554. https://doi.org/10.1177/2373997516646554.

71. La Regina M. Strumenti per una gestione sicura delle procedure invasive. Ital J Med. 2019;7(6):121-2.

72. Gotlib Conn L, Reeves S, Dainty K, Kenaszchuk C, Zwarenstein M. Interprofessional communication with hospitalist and consultant physicians in general internal medicine: a qualitative study. BMC Health Serv Res. 2012;12:437. https://doi. org/10.1186/1472-6963-12-437.

73. Conn LG, Lingard L, Reeves S, Miller KL, Russell A, Zwarenstein M. Communication channels in general internal medicine: a description of baseline patterns for improved interprofessional collaboration. Qual Health Res. 2009;19(7):943-53. https://doi. org/10.1177/1049732309338282.

74. The Joint Commission. Sentinel event alert. 2017. https://www.jointcommission.org/assets/1/18/ SEA_58_Hand_off_Comms_9_6_17_FINAL_(1). pdf. Last accessed 25 Oct 2019.

75. Joint Commission Center for Transforming Healthcare. Improving transitions of care: hand-off communications. 2014. https://psnet.ahrq.gov/issue/ improving-transitions-care-hand-communications. Last accessed 25 Oct 2019.

76. Riesenberg LA, Leitzsch J, Little BW. Systematic review of handoff mnemonics literature. Am J Med Qual. 2009;24(3):196-204. https://doi. org/10.1177/1062860609332512.

77. Haig KM, Sutton S, Whittington J. SBAR: a shared mental model for improving communication between clinicians. Jt Comm J Qual Patient Saf. 2006;32(3):167-75.

78. Starmer AJ, Spector ND, Srivastava R, West DC, Rosenbluth G, Allen AD, et al. Changes in medical errors after implementation of a handoff program. N Engl J Med. 2014;371(19):1803-12. https://doi. org/10.1056/NEJMsa1405556.

79. O’Toole JK, Starmer AJ, Calaman S, Campos ML, Hepps J, Lopreiato JO, et al. I-PASS mentored implementation handoff curriculum: champion training materials. MedEdPORTAL. 2019;15:10794. https://doi.org/10.15766/mep_2374-8265.10794.

80. Royal College of Physicians, Royal College of Nursing. Ward rounds in medicine: principles for best practice. 2012. https://www.rcplondon.ac.uk/ projects/outputs/ward-rounds-medicine-principlesbest-practice. Last accessed 25 Oct 2019.

81. Iedema R, Sorensen R, Braithwaite J, Flabouris A, Turnbull L. The teleo-affective limits of end-oflife care in the intensive care unit. Soc Sci Med. 2005;60(4):845-57. socscimed.2004.06.024.

82. Triggle N. Call to make ward rounds 'cornerstone of hospital care'. 2012. https://www.bbc.com/news/ health-19816017. Last accessed 25 Oct 2019.

83. Weber H, Stockli M, Nubling M, Langewitz WA. Communication during ward rounds in internal medicine. An analysis of patient-nursephysician interactions using RIAS. Patient Educ Couns. 2007;67(3):343-8. https://doi.org/10.1016/j. pec.2007.04.011.

84. Mathioudakis A, Rousalova I, Gagnat AA, Saad N, Hardavella G. How to keep good clinical records. Breathe (Sheff). 2016;12(4):369-73. https://doi. org/10.1183/20734735.018016.

85. Shekelle PG, Pronovost PJ, Wachter RM, McDonald KM, Schoelles K, Dy SM, et al. The top patient safety strategies that can be encouraged for adoption now. Ann Intern Med. 2013;158(5 Pt 2):365-8. https://doi. org/10.7326/0003-4819-158-5-201303051-00001.

86. Shojania KG, Duncan BW, McDonald JM, Wachter RM. Making health care safer: a critical analysis of patient safety practices. 2001. http://citeseerx.ist. psu.edu/viewdoc/download?doi=10.1.1.125.2605\&r ep=rep1\&type=pdf. 25 Oct 2019.

87. Nardi R., Tirotta D., Pinna G., Pirin G. Prevenzione dei rischi in Medicina Interna, casi particolari: atti autolesivi, vagabondaggio, intrappolamento nel paziente ospedalizzato, in: Rischio clinico in sanità e prevenzione dei rischi del paziente ricoverato in ospedale. Quad Int J Med. 2019.

88. Oliver D, Daly F, Martin FC, McMurdo ME. Risk factors and risk assessment tools for falls in hospital in-patients: a systematic review. Age Ageing. 2004;33(2):122-30. https://doi.org/10.1093/ageing/afh017.

89. Falls: assessment and prevention of falls in older people. National Institute for Health and Care Excellence: clinical guidelines. London; 2013.

90. Haines TP, Hill K, Walsh W, Osborne R. Designrelated bias in hospital fall risk screening tool predictive accuracy evaluations: systematic review and meta-analysis. J Gerontol A Biol Sci Med Sci. 2007;62(6):664-72. https://doi.org/10.1093/ gerona/62.6.664.

91. Miake-Lye IM, Hempel S, Ganz DA, Shekelle PG. Inpatient fall prevention programs as a patient safety strategy: a systematic review. Ann Intern Med. 2013;158(5 Pt 2):390-6. https://doi. org/10.7326/0003-4819-158-5-201303051-00005.

92. Rowe MA, Glover JC. Antecedents, descriptions and consequences of wandering in cognitively-impaired adults and the Safe Return (SR) program. Am J Alzheimers Dis Other Dement. 2001;16(6):344-52. https://doi.org/10.1177/153331750101600610. 
93. Cipriani G, Lucetti C, Nuti A, Danti S. Wandering and dementia. Psychogeriatrics. 2014;14(2):135-42. https://doi.org/10.1111/psyg.12044.

94. Rowe M. Wandering in hospitalized older adults: identifying risk is the first step in this approach to preventing wandering in patients with dementia. Am J Nurs. 2008;108(10):62-70; quiz 1. https://doi. org/10.1097/01.NAJ.0000336968.32462.c9.

95. Borbasi S, Jones J, Lockwood C, Emden C. Health professionals' perspectives of providing care to people with dementia in the acute setting: toward better practice. Geriatr Nurs. 2006;27(5):300-8. https:// doi.org/10.1016/j.gerinurse.2006.08.013.

96. Sheth HS, Krueger D, Bourdon S, Palmer RM. A new tool to assess risk of wandering in hospitalized patients. J Gerontol Nurs. 2014;40(3):28-33; quiz 4-5. https://doi. org/10.3928/00989134-20140128-06.

97. Hospital beds-risk of patient entrapment. 2017. https://healthycanadians.gc.ca/recall-alert-rappelavis/hc-sc/2017/62960a-eng.php. Last accessed 16 Aug 2019.

98. Todd JF. Waking up to hospital bed entrapment risks. Nursing. 2008;38(1):14-5. https://doi. org/10.1097/01.NURSE.0000305896.81298.69.

99. DiBardino DM, Wunderink RG. Aspiration pneumonia: a review of modern trends. J Crit Care. 2015;30(1):40-8. https://doi.org/10.1016/j. jcrc.2014.07.011.

100. Mandell LA, Niederman MS. Aspiration pneumonia. N Engl J Med. 2019;380(7):651-63. https://doi. org/10.1056/NEJMra1714562.

101. Son YG, Shin J, Ryu HG. Pneumonitis and pneumonia after aspiration. J Dent Anesth Pain Med. 2017;17(1):1-12. https://doi.org/10.17245/ jdapm.2017.17.1.1.

102. Herzig SJ, LaSalvia MT, Naidus E, Rothberg MB, Zhou W, Gurwitz JH, et al. Antipsychotics and the risk of aspiration pneumonia in individuals hospitalized for nonpsychiatric conditions: a cohort study. J Am Geriatr Soc. 2017;65(12):2580-6. https://doi. org/10.1111/jgs. 15066 .

103. Hannawi Y, Hannawi B, Rao CP, Suarez JI, Bershad EM. Stroke-associated pneumonia: major advances and obstacles. Cerebrovasc Dis. 2013;35(5):430-43. https://doi.org/10.1159/000350199.

104. Taylor JK, Fleming GB, Singanayagam A, Hill AT, Chalmers JD. Risk factors for aspiration in community-acquired pneumonia: analysis of a hospitalized UK cohort. Am J Med. 2013;126(11):995-1001. https://doi.org/10.1016/j. amjmed.2013.07.012.

105. van der Maarel-Wierink CD, Vanobbergen JN, Bronkhorst EM, Schols JM, de Baat C. Metaanalysis of dysphagia and aspiration pneumonia in frail elders. J Dent Res. 2011;90(12):1398-404. https://doi.org/10.1177/0022034511422909.

106. Momosaki R. Rehabilitative management for aspiration pneumonia in elderly patients. J Gen Fam Med. 2017;18(1):12-5. https://doi.org/10.1002/jgf2.25.
107. Ohkubo T, Chapman N, Neal B, Woodward M, Omae T, Chalmers J, et al. Effects of an angiotensinconverting enzyme inhibitor-based regimen on pneumonia risk. Am J Respir Crit Care Med. 2004;169(9):1041-5. https://doi.org/10.1164/ rccm.200309-12190C.

108. Passaro L, Harbarth S, Landelle C. Prevention of hospital-acquired pneumonia in non-ventilated adult patients: a narrative review. Antimicrob Resist Infect Control. 2016;5:43. https://doi.org/10.1186/ s13756-016-0150-3.

109. Kaneoka A, Pisegna JM, Miloro KV, Lo M, Saito $\mathrm{H}$, Riquelme LF, et al. Prevention of healthcareassociated pneumonia with oral care in individuals without mechanical ventilation: a systematic review and meta-analysis of randomized controlled trials. Infect Control Hosp Epidemiol. 2015;36(8):899906. https://doi.org/10.1017/ice.2015.77.

110. Higashiguchi T, Ohara H, Kamakura Y, Kikutani T, Kuzuya M, Enoki H, et al. Efficacy of a new postmouthwash intervention (wiping plus oral nutritional supplements) for preventing aspiration pneumonia in elderly people: a multicenter, randomized, comparative trial. Ann Nutr Metab. 2017;71(3-4):253-60. https://doi.org/10.1159/000485044.

111. Juthani-Mehta M, Van Ness PH, McGloin J, Argraves $\mathrm{S}$, Chen S, Charpentier P, et al. A cluster-randomized controlled trial of a multicomponent intervention protocol for pneumonia prevention among nursing home elders. Clin Infect Dis. 2015;60(6):849-57. https://doi.org/10.1093/cid/ciu935.

112. Valles J, Peredo R, Burgueno MJ, Rodrigues de Freitas AP, Millan S, Espasa M, et al. Efficacy of single-dose antibiotic against early-onset pneumonia in comatose patients who are ventilated. Chest. 2013;143(5):1219-25. https://doi.org/10.1378/ chest.12-1361.

113. Reston JT, Schoelles KM. In-facility delirium prevention programs as a patient safety strategy: a systematic review. Ann Intern Med. 2013;158(5 Pt 2):375-80. https://doi. org/10.7326/0003-4819-158-5-201303051-00003.

114. Oh ES, Fong TG, Hshieh TT, Inouye SK. Delirium in older persons: advances in diagnosis and treatment. JAMA. 2017;318(12):1161-74. https://doi. org/10.1001/jama.2017.12067.

115. Hshieh TT, Yue J, Oh E, Puelle M, Dowal S, Travison $\mathrm{T}$, et al. Effectiveness of multicomponent nonpharmacological delirium interventions: a meta-analysis. JAMA Intern Med. 2015;175(4):512-20. https://doi. org/10.1001/jamainternmed.2014.7779.

116. Neufeld KJ, Yue J, Robinson TN, Inouye SK, Needham DM. Antipsychotic medication for prevention and treatment of delirium in hospitalized adults: a systematic review and meta-analysis. J Am Geriatr Soc. 2016;64(4):705-14. https://doi.org/10.1111/ jgs. 14076 .

117. Hovaguimian F, Tschopp C, Beck-Schimmer B, Puhan M. Intraoperative ketamine administration to prevent delirium or postoperative cognitive dysfunc- 
tion: a systematic review and meta-analysis. Acta Anaesthesiol Scand. 2018;62(9):1182-93. https:// doi.org/10.1111/aas.13168.

118. Siddiqi N, Harrison JK, Clegg A, Teale EA, Young $\mathrm{J}$, Taylor J, et al. Interventions for preventing delirium in hospitalised non-ICU patients. Cochrane Database Syst Rev. 2016;3:CD005563. https://doi. org/10.1002/14651858.CD005563.pub3.

119. Teale E, Young J. Multicomponent delirium prevention: not as effective as NICE suggest? Age Ageing. 2015;44(6):915-7. https://doi.org/10.1093/ageing/ afv120.

120. Harbarth S, Sax H, Gastmeier P. The preventable proportion of nosocomial infections: an overview of published reports. J Hosp Infect. 2003;54(4):25866; quiz 321.

121. Al-Tawfiq JA, Tambyah PA. Healthcare associated infections (HAI) perspectives. J Infect Public Health. 2014;7(4):339-44. https://doi.org/10.1016/j. jiph.2014.04.003.

122. Allegranzi B, Storr J, Dziekan G, Leotsakos A, Donaldson L, Pittet D. The first global patient safety challenge "clean care is safer care": from launch to current progress and achievements. J Hosp Infect. 2007;65(Suppl 2):115-23. https://doi.org/10.1016/ S0195-6701(07)60027-9.

123. Mehta Y, Gupta A, Todi S, Myatra S, Samaddar DP, Patil V, et al. Guidelines for prevention of hospital acquired infections. Indian $\mathrm{J}$ Crit Care Med. 2014;18(3):149-63. https://doi. org/10.4103/0972-5229.128705.

124. Heit JA, Silverstein MD, Mohr DN, Petterson TM, O'Fallon WM, Melton LJ 3rd. Risk factors for deep vein thrombosis and pulmonary embolism: a population-based case-control study. Arch Intern Med. 2000;160(6):809-15. https://doi.org/10.1001/ archinte.160.6.809.

125. Kahn SR, Lim W, Dunn AS, Cushman M, Dentali F, Akl EA, et al. Prevention of VTE in nonsurgical patients: antithrombotic therapy and prevention of thrombosis, 9th ed: American College of Chest Physicians Evidence-Based Clinical Practice Guidelines. Chest. 2012;141(2 Suppl):e195S-226S. https://doi.org/10.1378/chest.11-2296.

126. Prandoni P, Samama MM. Risk stratification and venous thromboprophylaxis in hospitalized medical and cancer patients. $\mathrm{Br} \mathrm{J}$ Haematol. 2008;141(5):587-97. https://doi. org/10.1111/j.1365-2141.2008.07089.x.

127. Decousus H, Tapson VF, Bergmann JF, Chong $\mathrm{BH}$, Froehlich JB, Kakkar AK, et al. Factors at admission associated with bleeding risk in medical patients: findings from the IMPROVE investigators. Chest. 2011;139(1):69-79. https://doi.org/10.1378/ chest.09-3081.

128. La Regina M, Orlandini F, Marchini F, Marinaro A, Bonacci R, Bonanni P, et al. Combined assessment of thrombotic and haemorrhagic risk in acute medical patients. Thromb Haemost. 2016;115(2):392-8. https://doi.org/10.1160/TH14-12-1050.
129. Gussoni G, Campanini M, Silingardi M, Scannapieco G, Mazzone A, Magni G, et al. In-hospital symptomatic venous thromboembolism and antithrombotic prophylaxis in internal medicine. Findings from a multicenter, prospective study. Thromb Haemost. 2009;101(5):893-901.

130. Tincani E, Crowther MA, Turrini F, Prisco D. Prevention and treatment of venous thromboembolism in the elderly patient. Clin Interv Aging. 2007;2(2):237-46.

131. Samama MM, Cohen AT, Darmon JY, Desjardins L, Eldor A, Janbon C, et al. A comparison of enoxaparin with placebo for the prevention of venous thromboembolism in acutely ill medical patients. Prophylaxis in medical patients with enoxaparin study group. N Engl J Med. 1999;341(11):793-800. https://doi.org/10.1056/NEJM199909093411103.

132. Rondina MT, Wheeler M, Rodgers GM, Draper L, Pendleton RC. Weight-based dosing of enoxaparin for VTE prophylaxis in morbidly obese, medicallyill patients. Thromb Res. 2010;125(3):220-3. https:// doi.org/10.1016/j.thromres.2009.02.003.

133. Imberti D, Legnani C, Baldini E, Cini M, Nicolini A, Guerra M, et al. Pharmacodynamics of low molecular weight heparin in patients undergoing bariatric surgery: a prospective, randomised study comparing two doses of parnaparin (BAFLUX study). Thromb Res. 2009;124(6):667-71. https://doi.org/10.1016/j. thromres.2009.04.021.

134. Schmid P, Brodmann D, Fischer AG, Wuillemin WA. Study of bioaccumulation of dalteparin at a prophylactic dose in patients with various degrees of impaired renal function. J Thromb Haemost. 2009;7(4):552-8. https://doi. org/10.1111/j.1538-7836.2009.03292.x.

135. Turpie AG, Lensing AW, Fuji T, Boyle DA. Pharmacokinetic and clinical data supporting the use of fondaparinux $1.5 \mathrm{mg}$ once daily in the prevention of venous thromboembolism in renally impaired patients. Blood Coagul Fibrinolysis. 2009;20(2):114-21. https://doi.org/10.1097/ MBC.0b013e328323da86.

136. Mosarla RC, Vaduganathan M, Qamar A, Moslehi J, Piazza G, Giugliano RP. Anticoagulation strategies in patients with cancer: JACC review topic of the week. J Am Coll Cardiol. 2019;73(11):1336-49. https://doi.org/10.1016/j.jacc.2019.01.017.

137. Sullivan N, Schoelles KM. Preventing infacility pressure ulcers as a patient safety strategy: a systematic review. Ann Intern Med. 2013;158(5 Pt 2):410-6. https://doi. org/10.7326/0003-4819-158-5-201303051-00008.

138. Moore ZE, Patton D. Risk assessment tools for the prevention of pressure ulcers. Cochrane Database Syst Rev. 2019;1:CD006471. https://doi. org/10.1002/14651858.CD006471.pub4.

139. Insitute for Healthcare Improvement. What is a bundle? 2016. www.ihi.org/knowledge/Pages/ ImprovementStories/WhatIsaBundle.apsx. Last accessed 28 Oct 2019. 
140. Lyder CH, Ayello EA. Annual checkup: the CMS pressure ulcer present-on-admission indicator. Adv Skin Wound Care. 2009;22(10):476-84. https://doi. org/10.1097/01.ASW.0000361385.97489.51.

141. Jankowski IM, Nadzam DM. Identifying gaps, barriers, and solutions in implementing pressure ulcer prevention programs. Jt Comm J Qual Patient Saf. 2011;37(6):253-64.

142. Buist M, Bernard S, Nguyen TV, Moore G, Anderson J. Association between clinically abnormal observations and subsequent in-hospital mortality: a prospective study. Resuscitation. 2004;62(2):137-41. https://doi.org/10.1016/j. resuscitation.2004.03.005.

143. Goldhill DR, McNarry AF. Physiological abnormalities in early warning scores are related to mortality in adult inpatients. Br J Anaesth. 2004;92(6):882-4. https://doi.org/10.1093/bja/aeh113.

144. Kause J, Smith G, Prytherch D, Parr M, Flabouris A, Hillman K, et al. A comparison of antecedents to cardiac arrests, deaths and emergency intensive care admissions in Australia and New Zealand, and the United Kingdom-the ACADEMIA study. Resuscitation. 2004;62(3):275-82. https://doi. org/10.1016/j.resuscitation.2004.05.016.

145. Jansen JO, Cuthbertson BH. Detecting critical illness outside the ICU: the role of track and trigger systems. Curr Opin Crit Care. 2010;16(3):184-90. https://doi.org/10.1097/MCC.0b013e328338844e.

146. Groarke JD, Gallagher J, Stack J, Aftab A, Dwyer C, McGovern R, et al. Use of an admission early warning score to predict patient morbidity and mortality and treatment success. Emerg Med J. 2008;25(12):8036. https://doi.org/10.1136/emj.2007.051425.

147. Ludikhuize J, Brunsveld-Reinders AH, Dijkgraaf MG, Smorenburg SM, de Rooij SE, Adams R, et al. Outcomes associated with the nationwide introduction of rapid response systems in the Netherlands. Crit Care Med. 2015;43(12):2544-51. https://doi. org/10.1097/CCM.0000000000001272.

148. Correia N, Rodrigues RP, Sa MC, Dias P, Lopes L, Paiva A. Improving recognition of patients at risk in a Portuguese general hospital: results from a preliminary study on the early warning score. Int J Emerg Med. 2014;7:22. https://doi.org/10.1186/ s12245-014-0022-7.

149. Jarvis S, Kovacs C, Briggs J, Meredith P, Schmidt PE, Featherstone PI, et al. Aggregate National Early Warning Score (NEWS) values are more important than high scores for a single vital signs parameter for discriminating the risk of adverse outcomes. Resuscitation. 2015;87:75-80. https:// doi.org/10.1016/j.resuscitation.2014.11.014.

150. Smith GB, Prytherch DR, Schmidt PE, Featherstone PI. Review and performance evaluation of aggregate weighted 'track and trigger' systems. Resuscitation. 2008;77(2):170-9. https://doi.org/10.1016/j. resuscitation.2007.12.004.

151. Royal College of Physicians London. National Early Warning Score (NEWS): standardising the assess- ment of acute-illness severity in the NHS. Report of working party. London: Royal College of Physicians; 2012.

152. Tirkkonen J, Yla-Mattila J, Olkkola KT, Huhtala H, Tenhunen J, Hoppu S. Factors associated with delayed activation of medical emergency team and excess mortality: an Utstein-style analysis. Resuscitation. 2013;84(2):173-8. https://doi. org/10.1016/j.resuscitation.2012.09.021.

153. Watkinson PJ, Barber VS, Price JD, Hann A, Tarassenko L, Young JD. A randomised controlled trial of the effect of continuous electronic physiological monitoring on the adverse event rate in high risk medical and surgical patients. Anaesthesia. 2006;61(11):1031-9. https://doi. org/10.1111/j.1365-2044.2006.04818.x.

154. London RCoP. National Early Warning Score (NEWS): standardising the assessment of acuteillness severity in the NHS. Report of working party. London: Royal College of Physicians; 2012.

155. Davies O, DeVita MA, Ayinla R, Perez X. Barriers to activation of the rapid response system. Resuscitation. 2014;85(11):1557-61. https://doi. org/10.1016/j.resuscitation.2014.07.013.

156. Shearer B, Marshall S, Buist MD, Finnigan M, Kitto S, Hore T, et al. What stops hospital clinical staff from following protocols? An analysis of the incidence and factors behind the failure of bedside clinical staff to activate the rapid response system in a multi-campus Australian metropolitan healthcare service. BMJ Qual Saf. 2012;21(7):569-75. https:// doi.org/10.1136/bmjqs-2011-000692.

157. Bunkenborg G, Samuelson K, Akeson J, Poulsen I. Impact of professionalism in nursing on inhospital bedside monitoring practice. J Adv Nurs. 2013;69(7):1466-77. https://doi.org/10.1111/ jan. 12003 .

158. Jones L, King L, Wilson C. A literature review: factors that impact on nurses' effective use of the Medical Emergency Team (MET). J Clin Nurs. 2009;18(24):3379-90. https://doi. org/10.1111/j.1365-2702.2009.02944.x.

159. Rhodes A, Evans LE, Alhazzani W, Levy MM, Antonelli M, Ferrer R, et al. Surviving sepsis campaign: international guidelines for management of sepsis and septic shock: 2016. Intensive Care Med. 2017;43(3):304-77. https://doi.org/10.1007/ s00134-017-4683-6.

160. Dellinger RP, Carlet JM, Masur H, Gerlach H, Calandra T, Cohen J, et al. Surviving sepsis campaign guidelines for management of severe sepsis and septic shock. Crit Care Med. 2004;32(3):858-73. https://doi.org/10.1097/01.ccm.0000117317.18092. e4.

161. Levy MM, Pronovost PJ, Dellinger RP, Townsend S, Resar RK, Clemmer TP, et al. Sepsis change bundles: converting guidelines into meaningful change in behavior and clinical outcome. Crit Care Med. 2004;32(11 Suppl):S595-7. https://doi. org/10.1097/01.ccm.0000147016.53607.c4. 
162. Improvement IfH. What is a bundle? 2016. www. ihi.org/knowledge/Pages/ImprovementStories/ WhatIsaBundle.apsx.

163. Seymour CW, Gesten F, Prescott HC, Friedrich ME, Iwashyna TJ, Phillips GS, et al. Time to treatment and mortality during mandated emergency care for sepsis. N Engl J Med. 2017;376(23):2235-44. https://doi.org/10.1056/NEJMoa1703058.

164. Dellinger RP, Levy MM, Carlet JM, Bion J, Parker MM, Jaeschke R, et al. Surviving sepsis campaign: international guidelines for management of severe sepsis and septic shock: 2008. Crit Care Med. 2008;36(1):296-327. https://doi.org/10.1097/01. CCM.0000298158.12101.41.

165. Dellinger RP, Levy MM, Rhodes A, Annane D, Gerlach H, Opal SM, et al. Surviving sepsis campaign: international guidelines for management of severe sepsis and septic shock, 2012. Intensive Care Med. 2013;39(2):165-228. https://doi.org/10.1007/ s00134-012-2769-8.

166. Levy MM, Evans LE, Rhodes A. The surviving sepsis campaign bundle: 2018 update. Crit Care Med. 2018;46(6):997-1000. https://doi.org/10.1097/ CCM.0000000000003119.

167. Kumar A. Systematic bias in meta-analyses of time to antimicrobial in sepsis studies. Crit Care Med. 2016;44(4):e234-5. https://doi.org/10.1097/ CCM.0000000000001512.

168. Casserly B, Phillips GS, Schorr C, Dellinger RP, Townsend SR, Osborn TM, et al. Lactate measurements in sepsis-induced tissue hypoperfusion: results from the surviving sepsis campaign database. Crit Care Med. 2015;43(3):567-73. https://doi. org/10.1097/CCM.0000000000000742.

169. Lyu X, Xu Q, Cai G, Yan J, Yan M. [Efficacies of fluid resuscitation as guided by lactate clearance rate and central venous oxygen saturation in patients with septic shock]. Zhonghua Yi Xue Za Zhi. 2015;95(7):496-500.

170. Jones AE, Shapiro NI, Trzeciak S, Arnold RC, Claremont HA, Kline JA, et al. Lactate clearance vs central venous oxygen saturation as goals of early sepsis therapy: a randomized clinical trial. JAMA. 2010;303(8):739-46. https://doi.org/10.1001/ jama.2010.158.

171. Zadroga R, Williams DN, Gottschall R, Hanson K, Nordberg V, Deike M, et al. Comparison of 2 blood culture media shows significant differences in bacterial recovery for patients on antimicrobial therapy. Clin Infect Dis. 2013;56(6):790-7. https://doi. org/10.1093/cid/cis1021.

172. Kleinpell R. Promoting early identification of sepsis in hospitalized patients with nurse-led protocols. Crit Care. 2017;21(1):10. https://doi.org/10.1186/ s13054-016-1590-0.

173. Goulding L, Adamson J, Watt I, Wright J. Lost in hospital: a qualitative interview study that explores the perceptions of NHS inpatients who spent time on clinically inappropriate hospital wards. Health Expect. 2015;18(5):982-94. https://doi.org/10.1111/ hex.12071.

174. Stylianou N, Fackrell R, Vasilakis C. Are medical outliers associated with worse patient outcomes? A retrospective study within a regional NHS hospital using routine data. BMJ Open. 2017;7(5):e015676. https://doi.org/10.1136/bmjopen-2016-015676.

175. Friends and Family test 2018-2019. https://www. southwestyorkshire.nhs.uk/about-us/performance/ friends-and-family-test/2018-19-annual-results/. Last accessed 25 Oct 2019.

176. The Newcastle upon Tyne Hospitals NHS Foundation TrustBed Management and Escalation Policy. 2016. http://www.newcastle-hospitals. org.uk/downloads/policies/Operational/ BedManagementPolicy201602.pdf. Last accessed 25 Oct 2019.

177. NHS Clinical Policies. Portsmouth Hospitals. https://www.porthosp.nhs.uk/about-us/policies-andguidelines/clinical-policies.htm. Last accessed 28 Oct 2019.

178. Knight S, Mallory MNS, Huecker MR. Medical mimics of psychiatric conditions-part 1. MDedge. 2016. www.emed-journal.com.

179. McKee J, Brahm N. Medical mimics: differential diagnostic considerations for psychiatric symptoms. Ment Health Clin. 2016;6(6):289-96. https://doi. org/10.9740/mhc.2016.11.289.

180. NICE Guideline. Care of dying adults in the last days of life. https://www.nice.org.uk/guidance/ng31/ resources/care-of-dying-adults-in-the-last-daysof-life-pdf-1837387324357. Last accessed 28 Oct 2019.

Open Access This chapter is licensed under the terms of the Creative Commons Attribution 4.0 International License (http://creativecommons.org/licenses/by/4.0/), which permits use, sharing, adaptation, distribution and reproduction in any medium or format, as long as you give appropriate credit to the original author(s) and the source, provide a link to the Creative Commons license and indicate if changes were made.

The images or other third party material in this chapter are included in the chapter's Creative Commons license, unless indicated otherwise in a credit line to the material. If material is not included in the chapter's Creative Commons license and your intended use is not permitted by statutory regulation or exceeds the permitted use, you will need to obtain permission directly from the copyright holder.

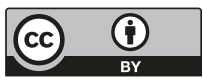

